\title{
DANGER ZONE: THE CAUSAL EFFECTS OF HIGH-DENSITY AND MIXED-USE DEVELOPMENT ON NEIGHBORHOOD CRIME
}

\author{
TATE TWINAM \\ Department of Economics \\ University of Pittsburgh
}

\begin{abstract}
Since the seminal work of Jane Jacobs, it has become conventional wisdom among scholars and professional planners that high residential density and mixed commercial and residential land use reduce street crime. This notion has been influential in guiding planning decisions, but empirical evidence is limited. This paper examines the impact of mixed land use and residential density on crime using a unique high-resolution dataset from Chicago over the period 2008-2013. I employ a novel instrumental variable strategy based on the city's 1923 zoning code. I find that commercial uses, especially liquor stores and late-hour bars, lead to more street crime in their immediate vicinity, with relatively weak spillover effects. Higher residential density leads to lower per capita crime rates and ameliorates the criminogenic externalities of commercial activity. I discuss the implications for zoning policy and policing strategy.
\end{abstract}

\section{INTRODUCTION}

Crime is an important determinant of the quality of neighborhoods and cities. A substantial portion of central-city depopulation beginning in the 1970s can be attributed directly to crime, and rising crime is associated with neighborhood decline and increased isolation of minorities within cities (Cullen and Levitt 1999, Morenoff and Sampson 1997). The negative consequences of these developments, such as deteriorating public services and higher rates of poverty, are well documented (Bradbury, Downs and Small 1982, Massey and Denton 1993). Many scholars and planners have embraced the notion that cities can use the considerable

E-mail address: tat47@pitt.edu.

Date: October 14, 2014.

JEL classification. K42, R14, R52.

Key words and phrases. Crime, land use, zoning, instrumental variables, matching.

I thank Arie Beresteanu, Randall Walsh, Allison Shertzer, Dennis Epple, and Brian Beach for helpful feedback on earlier drafts. I also thank Price Fishback, Brendan O'Flaherty, Elizabeth Ananat, and seminar participants at the University of Pittsburgh for helpful comments. I gratefully acknowledge financial support from an Andrew Mellon Predoctoral Fellowship and the Center for Race and Social Problems at the University of Pittsburgh. 
power of zoning to shape land use patterns in a manner that will cultivate safe, vibrant neighborhoods.

Since the seminal work of Jane Jacobs, it has become conventional wisdom among both academics and professional urban planners that mixing commercial and residential land uses will lead to fewer street crimes by increasing pedestrian traffic and generating more supervision of street activities (Jacobs 1961). Glaeser (2011) has argued that high residential densities should operate against crime through the same channel. These ideas have been widely influential in practice; for example, Mayor Bloomberg presided over the rezoning of $37 \%$ of New York City, much of it for high-density, mixed-use developments encouraged by these theories (Silverman 2013). Many other major cities, such as Houston, Texas and Vancouver, British Columbia, have embraced the trend towards mixed-use and high-density development (Punter 2007, Sarnoff and Kaplan 2007); even smaller cities such as Sarasota, Florida have pursued rezoning plans to generate greater pedestrian traffic in high-crime areas through a greater availability and variety of commercial uses (Carter, Carter and Dannenberg 2003). Anderson, MacDonald, Bluthenthal and Ashwood (2013) refer to the argument that commercial and mixed-use zoning reduce crime as a "common-sense notion" and Geraldine Pettersson claims that "most of the present-day assumptions about the relationship between mixed uses and crime prevention appear to draw heavily on the arguments of Jane Jacobs and little else" (Coupland 1997).

In contrast, criminologists emphasize that mixed uses and high residential density generate more contact between potential offenders and potential victims. The "routine activities" theory of Cohen and Felson (1979) argues that direct-contact predatory crime requires the "convergence in space and time of likely offenders, suitable targets and the absence of capable guardians," which is arguably more likely to occur in higher-density, mixed-use areas. Stark (1987) argues that mixed uses and high density result in greater transience, anonymity, and "moral cynicism among residents," reducing neighborhood collective efficacy. This follows a long tradition in the sociology literature of linking high densities to pathological behavior (Sampson 1983, Wirth 1938). Additionally, specific commercial uses such as bars and liquor 
stores may serve as crime generators (Roncek and Bell 1981). The fact that crime is typically concentrated on a small number of street segments and intersections ("hot spots") lends further credence to the notion that place characteristics can be criminogenic (Weisburd, Groff and Yang 2012). ${ }^{1}$

The empirical evidence for these theories is mixed, and existing studies suffer from a variety of measurement and identification problems. Since local governments exert substantial influence over the built environment through zoning, quantifying the criminogenic externalities of commercial and residential land use is of first-order importance. To this end, I study the effect of commercial and high-density residential use on street crime. I develop a unique high-resolution dataset on land use types in the City of Chicago using a comprehensive 2005 land use survey supplemented with exact locations and descriptions of every licensed restaurant, (late-hour) bar, and liquor store in the city. I combine this with detailed, spatially-referenced crime data covering all crime incidents over the period 2008-2013. My sample consists of approximately 20,000 street segments. This fine spatial scale implies that the analysis maps directly to the theory, allowing me to avoid the ecological inference problems which made the results of previous studies difficult to interpret. This approach also allows for the measurement of the spatial scale of land use effects, which has been largely ignored by the previous literature despite its important implications for the extent to which negative land use externalities can be mitigated through alternative policing strategies. I am also able to determine the extent to which the effect of commercial activity on crime is driven by particular uses, which has not been previously documented.

To address unobserved neighborhood characteristics and reverse causality, I employ an instrumental variables approach, using the city's 1923 zoning code as an instrument for modern land use. I show that historical zoning is a strong predictor of modern land use, and I validate the assumption of exogeneity by showing that unobservable neighborhood

\footnotetext{
${ }^{1}$ Sherman, Gartin and Buerger (1989) find that $3 \%$ of addresses/intersections in Minneapolis are resposible for $50 \%$ of calls to the police. Braga, Papachristos and Hureau (2010) find a similar result for gun crime in Boston and show that these hot spots tend to persist over long time horizons. This pattern has been documented in Seattle and Tel Aviv-Jaffa as well, suggesting that this is a general feature of urban areas (Weisburd and Amram 2014, Weisburd, Bushway, Lum and Yang 2004).
} 
characteristics affecting crime and zoning in the 1920s were not persistent. To identify the impact of specific commercial uses such as restaurants, (late-hour) bars, and liquor stores, I apply a spatial matching approach, examining how the level of crime differs within pairs of street segments that differ in their land use composition but are so proximate spatially that they arguably share the same unobservable neighborhood characteristics. Previous empirical studies in this area relied on a very limited set of control variables to account for neighborhood characteristics. This is the first study to use these more rigorous approaches to identify the causal effects of land use.

My results indicate that commercial uses lead to substantially more street robberies and batteries in their immediate vicinity. The spillover effect into neighboring areas is relatively small for robberies but more substantial for batteries and assaults. Liquor stores and latehour bars have large positive impacts on street robberies, while restaurants and bars have smaller but nontrivial positive effects. Even after accounting for these uses, there is a large residual impact of general commercial use on robberies. In contrast, the effect of commercial uses on batteries and assaults is almost entirely driven by the four specific uses I consider; restaurants and bars have moderately-sized effects while liquor stores and especially latehour bars have dramatic effects in their immediate vicinity. I find that sizable increases in population generate small increases in the number of street crime incidents so that per capita crime rates fall substantially with population. Higher residential density also appears to mitigate the criminogenic effect of commercial activity.

The experimental literature on hot spots policing provides some insight into how the criminogenic externalities of commercial land use might be curtailed. Randomized controlled trials have demonstrated that concentrating policing in a localized area of high crime can substantially reduce violent crime in that area without displacement to nearby areas (Braga and Weisburd 2010). Zoning could potentially be used to limit the number and diffusion of particularly criminogenic uses, facilitating the efficient use of police resources. My findings on the role of population density suggest that zoning which favors higher residential density could improve neighborhood safety, and that zoning which allows for mixed use structures 
may be preferable to more restrictive rules that aim for strictly commercial use. More broadly, my finding that land use is a sizable determinant of crime patterns further establishes the importance of understanding this relationship.

\section{Previous literature}

Economists have largely ignored intra-metropolitan variation in crime, instead focusing on temporal and inter-metropolitan variation (O'Flaherty and Sethi 2014). ${ }^{2}$ However, there is an extensive empirical literature in criminology and sociology on the relationship between crime and land use. Bernasco and Block (2009) study the location selection behavior of robbers in Chicago at the census tract level. Their results indicate that robbers frequently choose to offend in the census tract in which they reside or one which has a racial composition similar to that of their tract of residence; this is consistent with the interview-based evidence presented in Wright and Decker (1997). They find that individuals rarely travel far to offend and that census tracts with greater retail employment are more likely to be chosen. Browning, Byron, Calder, Krivo, Kwan, Lee and Peterson (2010) study the relationship between crime and commercial and residential density in a sample of census tracts from Columbus, Ohio. They find that, at low levels, an increase in a variable measuring commercial/residential density is associated with more crimes; at high levels, this relationship becomes negative.

Stucky and Ottensmann (2009) examine the relationship between violent crimes and land use patterns in Indianapolis. They find that robberies are much more common in commercial areas, even when the comparison is between commercial areas with above-average measured socioeconomic status and non-commercial areas with below-average socioeconomic status; however, they find the reverse pattern for homicides. Anderson et al. (2013) use zoning as a proxy for land use and study the relationship between crime, land use, and other built environment characteristics such as physical disorder, territoriality, and the condition of buildings, sidewalks, and streets. They measure the number of crimes within 100 and 250 meters of each of 205 blocks in Los Angeles County. They match blocks so that they have a

\footnotetext{
${ }^{2}$ There are some exceptions. Cui and Walsh (2014) show that residential foreclosures resulting in long-term vacancies increase violent crime nearby. O'Flaherty and Sethi (2010) develop a sorting model to explain the concentration of street vice (such as prostitution and drug selling) in poor central city neighborhoods.
} 
comparable demographic composition. They find that residential zoning is associated with less crime than mixed-use zoning, and that commercial zoning is associated with substantially more crime than mixed-use zoning.

Sampson (1983) argues that the defensible-space and routine-activities theories support the idea that high residential densities will lead to more violent crime. He tests this hypothesis using National Crime Survey victimization data combined with roughly tract-level data on the residential density experienced by the respondents. He finds the expected positive relationship. White (1990) studies neighborhood permeability and burglary; a secondary finding is that residential density is negatively associated with burglary rates.

Some studies have examined the extent to which specific commercial land uses attract crime. Using data from Cleveland, Roncek and Maier (1991) document that city blocks containing bars see substantially more violent and property crime. Bernasco and Block (2011) study the spatial pattern of street robberies in Chicago. Their measure of commercial land use is derived from retail business counts collected by the marketing firm Claritas. They focus on a subset of these businesses selected so that the proportion of cash transactions would be high; this subset includes small bars, fast-food restaurants, liquor stores, laundromats, as well as other businesses. They find that every in-block commercial use they measure has a statistically significant positive relationship with the number of robberies, as does almost every adjacent-block commercial use. Of particular relevance to my analysis, they find that bars, fast-food restaurants, and liquor stores are associated with more robberies.

I build on the existing literature in a number of respects. I emphasize the role of population density, which has been marginalized in previous work, and I study how the interaction of commercial land use and population density affects crime outcomes. The unique detail of my crime data allows me to separate street crimes from crimes occurring indoors, which has not been possible in previous work. Since robberies of commercial establishments can only occur where such establishments exist, separating street robberies from business robberies eliminates an clear source of bias. I also consider crimes disaggregated by type, which 
is advantageous if different crimes have different relationships to land use, as my results indicate.

My study aggregates crimes to very small units of observation that effectively capture the land use immediately surrounding the crimes while separately accounting for ambient, "down the street" land uses. This avoids the numerous problems associated with aggregating crime and land use measurements to larger geographic areas such as census tracts, the standard approach in the previous literature. Higher level aggregation leads to an ecological inference problem; one cannot use the results to determine if crimes are concentrated close to commercial uses. Higher level aggregation also eliminates the possibility of determining the spatial range of land use effects and exacerbates the problem of confounding by unmeasured neighborhood characteristics. Aggregating to the census block level, as some studies have done, is problematic as well; crimes that occurred on the residential side of a block could be associated with commercial uses on the other side of the block, despite the fact that these commercial uses are not proximate to the crime. Measuring land use at the block level also ignores the fact that crimes will be directly influenced by land use on proximate block faces. My approach to defining observations avoids these problems. I argue that my study is the first to effectively capture the spatial range of land use effects on crime; the few studies that measured crime and land use at the street segment or block face level failed to account for nearby land uses.

When estimating the impact of specific uses, such as bars and liquor stores, I account for the presence of general commercial uses. This allows me to precisely attribute differences in crime to the specific uses I consider; previous studies examining the role of specific uses did not account for the general commercial character of the area. It also allows me to estimate the "residual" effect of commercial activity after accounting for particularly criminogenic uses, a first in this literature. In my baseline specification, I include a wide variety of control variables not typically employed, such as counts of bus stops, which are strongly related to both commercial land use and street crime. In addition to using a much more complete set of 
control variables than existing studies, my study is the first to employ the more sophisticated instrumental variable and spatial matching approaches to identification.

\section{DATA}

This section describes the seven components of the dataset compiled for this paper. Land use data is drawn from two sources: A 2005 comprehensive survey of land use in Chicago and a registry of business licenses. Modern demographic data is derived from the 2010 Decennial Census as well as the American Community Survey. Crime data is derived from incident report records provided by the Chicago Police Department. Historical zoning data was geocoded from the original 1923 zoning ordinance and associated maps. Historical demographic data comes from the 1920 Decennial Census and the 1938 Local Community Fact Book. Historical homicide data is taken from the Chicago Historical Homicide Project. Historical land use data was geocoded from a comprehensive 1922 land use survey.

3.1. Land use. My primary land use data comes from a 2005 comprehensive survey conducted by the Chicago Metropolitan Agency for Planning (CMAP). From the CMAP classification I derive the following mutually exclusive and exhaustive land use categories: Singlefamily residential, multi-family residential, commercial (including residential with groundlevel retail), industrial, institutional, open space, transportation, infrastructure, vacant, and under construction. Virtually all of the land in the city is coded as residential, commercial, industrial, institutional, or open space. The variables included in the analysis are discussed in section 4.2 .

There are a number of reasons to believe that specific commercial uses may have an outsized effect on crime. I obtained data on specific uses from the registry of business licenses maintained by the Chicago Department of Business Affairs and Consumer Protection over the period 2008-2013. This registry includes coordinates which were used to geocode the establishments. I use data on the following license types: "Tavern," "Retail Food Establishment," "Late Hour," "Consumption on Premises - Incidental Activity," "Package Goods," 
and "Tobacco Retail Over Counter." I use the particular set of licenses held by an establishment to determine whether it is a restaurant, bar, late-hour bar, or liquor store. Details are relegated to the data appendix.

3.2. Demographics. Demographic data is drawn from the 2010 Decennial Census and the 2006-2010 American Community Survey. The 2010 Census provides total population counts, counts by race and Hispanic/Latino origin, age composition, and counts of housing units and tenure status at the block level. ${ }^{3}$ The 2006-2010 American Community Survey provides data on median household income, counts of individuals on public assistance, and poverty status. The block- and block-group-level data was attached to my sampling units via areal interpolation. Census data and associated GIS maps were taken from NHGIS.

3.3. Crime. Information on crimes is drawn from a publicly-accessible database of crime incident report data provided by the Chicago Police Department's Citizen Law Enforcement Analysis and Reporting system. It includes every instance of robbery, battery, and assault over the period 2008-2013 for which an incident report was filed. Robbery is defined as the intentional taking of property from a person "by the use of force or by threatening the imminent use of force." A person commits battery if they knowingly cause "bodily harm to an individual" or make "physical contact of an insulting or provoking nature with an individual." A person commits an assault when they knowingly engage in "conduct which places another in reasonable apprehension of receiving a battery."

The publicly-available data includes coordinates corresponding to the most proximate address, which were used to geocode the crimes. ${ }^{4}$ Crucial for my study is the fact that each incident report includes a brief description of the location of the crime, such as sidewalk, apartment, or small retail store. This location description allows me to isolate street robberies, assaults, and batteries from those occurring inside businesses.

3.4. Historical zoning. To deal with potential confounding between land use and crime, I adopt an instrumental variable approach, using Chicago's original 1923 zoning code as an

${ }^{3}$ Census blocks roughly correspond to standard city blocks throughout much of Chicago.

${ }^{4}$ There is no evidence that crimes were coarsely geocoded to, e.g., the nearest street intersection. 
instrument for modern land use. This was the city's first comprehensive zoning ordinance. The ordinance established districts regulating both land use types ("use districts") and building density ("volume districts"). Four use districts were created: Residential (single-family housing), apartment, commercial, and manufacturing. These use districts were hierarchical, with apartment districts allowing residential uses, commercial districts allowing both apartments and single-family homes, and manufacturing districts allowing any use. Figure 1a provides a sample of the 1923 use zoning map.

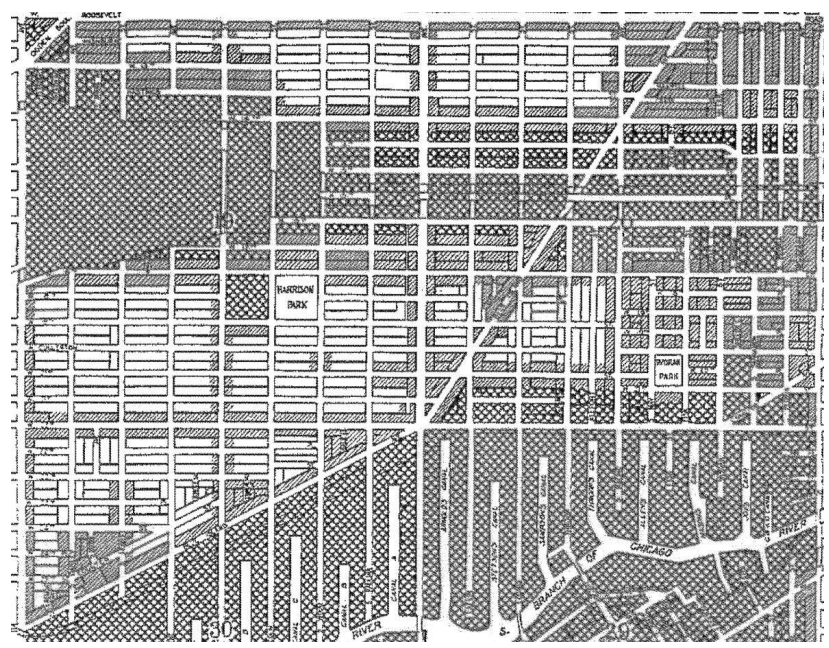

(A)

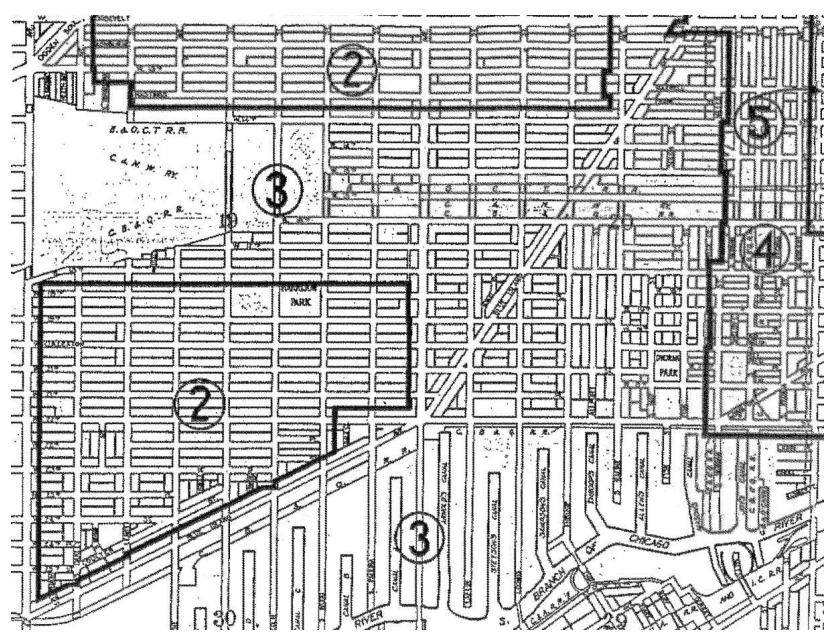

(B)

FIGURE 1. 1923 use and density zoning maps

Volume districts imposed restrictions on maximum lot coverage, aggregate volume, and height. Five volume districts were established, with district 1 restricted to the lowest density 
while district 5 permitted skyscrapers. Figure 1b provides a sample of the 1923 volume zoning map. Shertzer, Twinam and Walsh (2014b) demonstrate that this zoning ordinance had a substantial causal effect on the spatial evolution of land use patterns in Chicago. This makes the zoning code a powerful instrument, as I document in section 4.3.3. The specific variables I derive from the zoning ordinance are discussed in section 4.3.1.

3.5. Historical land use. In section 4.3.4, I use historical land use data as part of a test for persistent unobservable neighborhood characteristics which may influence crime. I geocoded this data from a comprehensive 1922 land use survey conducted by the Chicago Zoning Commission to inform the process of drafting the 1923 zoning ordinance. This data contains the location of every commercial and manufacturing use in the city, with the latter subdivided into five subcategories, as well as the location and number of stories for every building with four or more stories.

3.6. Historical demographics. During the late 1920's, a group of sociologists at the University of Chicago divided the city into 75 mutually exclusive and exhaustive "community areas." These were considered "natural areas," the divisions reflecting distinct and identifiable clusters of related neighborhoods (Bulmer 1986). I use fixed effects based on these community areas to partially mitigate biases due to unmeasured neighborhood characteristics.

The Chicago Recreation Committee prepared an extensive handbook on community area characteristics in 1930 and 1934 for use by civic and social agencies; the 1938 Local Community Fact Book that resulted contains data on the share of households receiving public assistance, which I utilize in section 4.3.4 to argue for the validity of my instrumental variables strategy (Wirth and Furez 1938). Historical data on tract-level population and racial composition comes from the 1920 Decennial Census. The data and associated GIS maps were taken from NHGIS.

3.7. Historical crime. In section 4.3.4, I compare historical and modern patterns of homicide to argue for the validity of my instrumental variables strategy. Historical homicide data 
is taken from the Chicago Historical Homicide Project, which digitized a continuous record of approximately 11,000 homicide cases maintained by the Chicago Police Department over the period 1870-1930 (Bienen and Rottinghaus 2002). Many of these records contained an address for the location of the crime. 4,528 of these were geocoded to a specific street address, while another 742 were matched to the nearest street intersection. Of these 5,270 homicides, 4,290 are dated between 1910 and 1930 .

\section{Methodology}

In section 4.1, I define and motivate my unit of observation. In section 4.2, I describe the basic empirical approach. In section 4.3, I outline my instrumental variable strategy and provide evidence for the relevance and exogeneity of the instruments. In section 4.4, I present a solution to the problem of identifying the effects of specific commercial uses based on matching proximate observations.

4.1. Unit of observation. The goal of the empirical analysis is to determine the effect of proximate and nearby commercial uses on crime, as well as the influence of population density and the interaction of these effects. Given a small street segment, I want to know if commercial uses on the street segment influence crime, and I want to contrast this effect with that of more distant commercial uses. Theory suggests that commercial uses may affect crime in their immediate vicinity by increasing pedestrian traffic and contributing to social norm enforcement via monitoring by business proprietors. Commercial uses may have an effect over a longer range by generating street traffic that spills over into neighboring residential areas. The ideal unit of observation should capture crimes and their immediate surrounding land uses while also measuring proximity to neighboring land use types. For example, crimes that occurred in front of a commercial establishment should be distinguishable from crimes that occurred in front of a home but down the street from a commercial use, and these latter crimes should be distinguishable from crimes that occurred in isolated residential areas.

To accomplish this, I aggregate crimes within small (300-ft-wide) street-centered circles and measure the land use within these circles. The circles are small enough so that the 


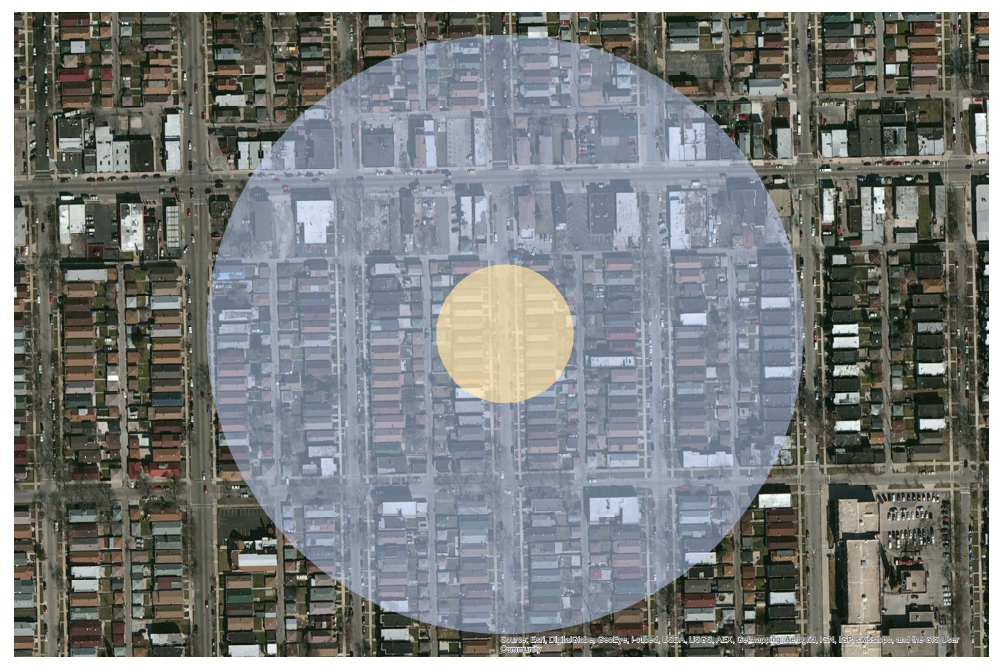

FiguRE 2. Sample unit of observation with annulus

land use captured is only that which immediately surrounds the location of the crimes. ${ }^{5}$ To analyze the spatial range of effects, I also measure land use in an annulus extending 500 feet from the boundary of each circle. This captures the effect of "down the street" land uses. An example is given in figure 2.

These (non-overlapping) circles are centered on points selected along the street grid. Ideally, my sample would cover the entire street area in the portion of the city for which I have data. However, this is not feasible, since it would be impossible to avoid generating circles that overlap. The algorithm I use approximates this ideal:

(1) Start with all street intersections and midpoints.

(2) Drop midpoints within 300 feet of an intersection.

(3) Drop intersections within 300 feet of each other.

(4) Randomly sample points on portions of the street grid that are more than 300 feet away from any remaining points.

The first three steps of this algorithm yield a dense, regular array of sample points in the majority of the city, due to the ubiquitous rectangular grid street system. An example is given in figure $3 \mathrm{a}$. In the portions of the city with an irregular street grid, the sample points are less densely packed. An example is given in figure $3 \mathrm{~b}$.

${ }^{5}$ This method also ensures that the land use on the sides of the street opposite the location of the crime are effectively captured, which is not the case when census blocks are used as the unit of analysis. 


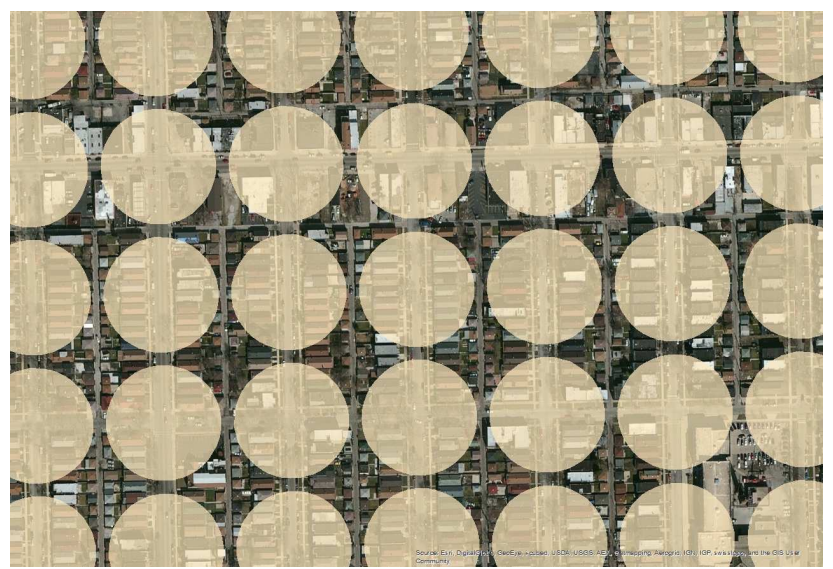

(A)

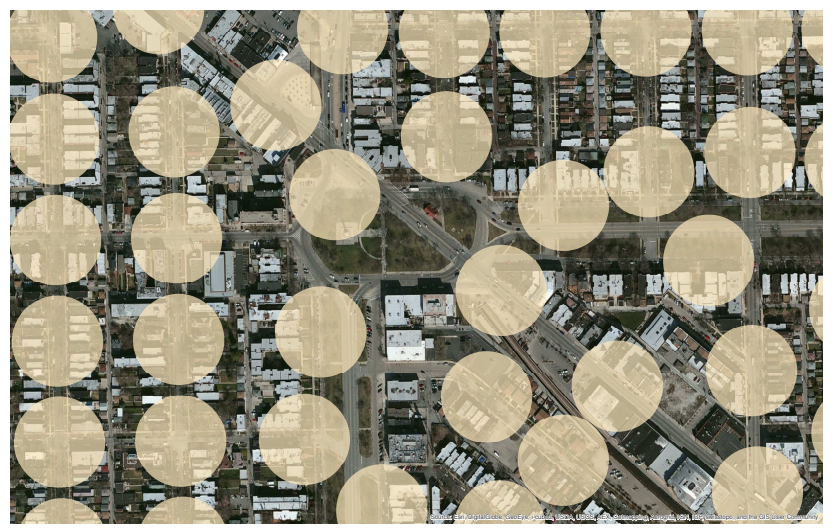

(B)

FIGURE 3. Sampling in regular and irregular portions of the street grid

My circle-level data consists of crime counts as well as land use (including counts of business types) and housing data. I also measure ambient land use and businesses in the 500-foot annulus. Demographic data is attached to the combined circle-annulus area via areal interpolation.

Figure 4 shows the portion of the city for which I have data. This area includes the central business district and surrounding environs, including the historic Black Belt. It also includes many of the largely black or Hispanic enclaves that have developed since the early twentieth century. Since the core of the central business district and the waterfront are not representative of the city as a whole, I exclude circles whose annuli overlap the central business district or lie within 500 feet of Lake Michigan. 


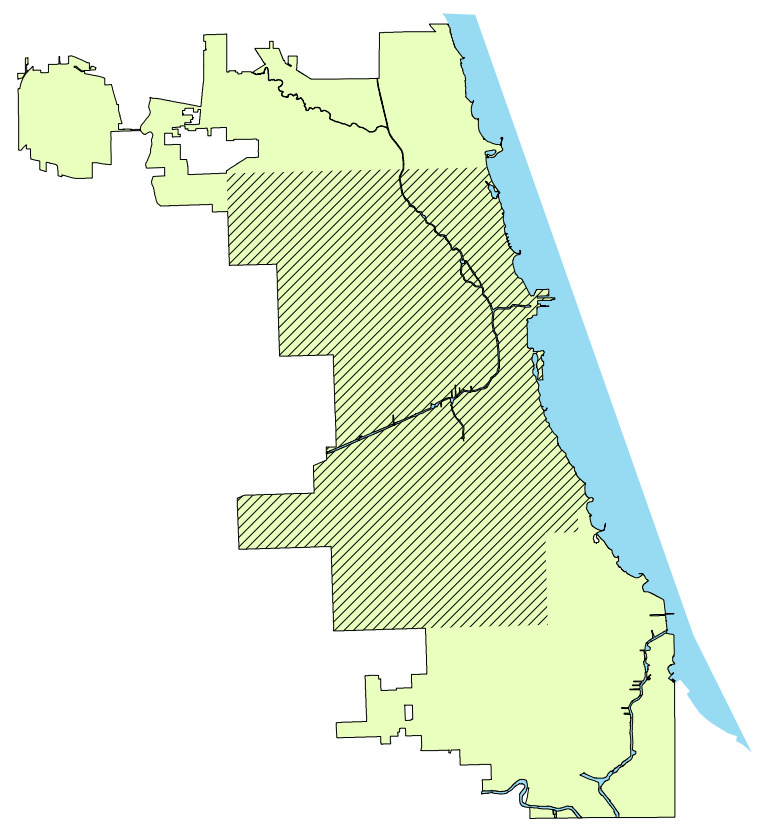

Figure 4. Sample area within Chicago

4.2. Estimation: Baseline specification. The main outcomes of interest are counts of specific street crimes such as robbery, battery, and assault. I estimate models of street crimes on the full sample to determine the effect of commercial uses on crime in their immediate area; I also estimate these models on a subset of sample circles that contain only residential uses to determine the extent to which neighboring commercial uses have a spillover effect.

A Poisson regression is the standard approach for analyzing data with nonnegative outcomes (Cameron and Trivedi 2013). This approach assumes that the pdf of the data generating process is

$$
f\left(y_{i} \mid x_{i}\right)=\frac{e^{-e^{x_{i}^{\prime} \beta}} e^{x_{i}^{\prime} \beta y_{i}}}{y_{i} !}, \quad i \in\{1,2, \ldots, n\}
$$

This implies that

$$
\mathrm{E}\left[y_{i} \mid x_{i}\right]=e^{x_{i}^{\prime} \beta}
$$


If this functional form is correctly specified, a consistent, efficient, and asymptotically normal estimator of $\beta$ can be obtained via maximum likelihood under standard regularity conditions (Cameron and Trivedi 2013). ${ }^{6}$

The primary explanatory variables of interest are the percentage of the circle and annulus occupied by commercial uses (including apartment buildings with ground-level retail) and the population density of the combined circle-annulus area. I allow population density to enter as a quadratic polynomial and I include an interaction between population density and the percentage of the circle occupied by commercial uses. Population density is standardized. Other land use variables include the percentage of the circle and annulus occupied by singlefamily residences and industrial uses; the share devoted to multi-family residences is left as the omitted category. I also include distances to the nearest commercial and industrial use. These are the primary land use variables, and I instrument for all of them in the second part of the empirical analysis. I also account for a variety of auxiliary land uses, such as the percentage of the circle and annulus occupied by institutional and large-scale transportation uses as well as the percentage that is vacant or open space.

I include an indicator for whether or not the circle contains a street intersection; Wright and Decker (1997) document that armed robbers prefer to commit offenses near intersections to allow for an easier escape. White (1990) suggests that neighborhood permeability, defined as access to major traffic arteries, may have a positive impact on crime, and he provides some evidence for this hypothesis. To account for this possibility, I include a measure of ambient street density, an indicator for location on a major street, a quadratic polynomial in the distance to a major street, and the percentage of the circle and annulus occupied by a major transportation corridor. The concentration of crime around bus stops is well documented (see, e.g., Loukaitou-Sideris (1999)), and bus stops are frequently located along streets occupied by commercial uses, so I include counts of bus stops in each circle.

\footnotetext{
${ }^{6}$ If (4.2) is correctly specified and standard regularity conditions hold, then the quasi-maximum likelihood estimator of $\beta$ is consistent and asymptotically normal even if (4.1) is misspecified, as is the case when overdispersion is present (Gourieroux, Monfort and Trognon 1984a,b, White 1982).
} 
Other control variables include the percentage of housing units which are vacant, the percentage which are owner-occupied, the percentage of the population that is black, Hispanic, or under 18 , the percentage of households with members over the age of 65 , and the average household size. The share of the population that is black or Hispanic is allowed to enter as a quadratic polynomial, and I also include an interaction between these shares as well as four indicator variables for highly segregated neighborhoods (those with shares black or Hispanic above $90 \%$ or below 10\%). A quadratic polynomial for the percentage of households on public assistance is included, as is the share of households falling into each of seven bins defined by household income relative to the poverty level. I include quadratic polynomials in the distance to the central business district, Lake Michigan, the nearest river, nearest railroad, nearest park, and the nearest CTA station. I also include community area fixed effects to mitigate the bias due to unmeasured neighborhood characteristics.

For ease of interpretation, reported estimates are average marginal effects of the variables of interest. For the interaction between commercial uses and population density, I report the average cross-partial derivative. I report robust standard errors for the baseline specification (White 1980). ${ }^{7}$

A Poisson regression is preferable to a standard linear regression for two reasons. First, the exponential conditional mean assumption (4.2) ensures that predicted values of $y$ will be nonnegative. Second, the Poisson model substantially outperforms the linear model in out-of-sample prediction. ${ }^{8}$ A negative binomial model is an alternative approach suited to count data, however it is more complex to estimate and does not offer a clear advantage over a simpler Poisson model (Blackburn 2014). ${ }^{9}$

4.3. Identification: Instrumental variables. To address the potential endogeneity of land use patterns, I adopt an instrumental variables strategy, using Chicago's 1923 zoning

${ }^{7}$ I also estimated these models using the Conley (1999) approach to adjust for spatial autocorrelation; the standard errors were similar.

${ }^{8}$ In a 2-fold cross-validation test using counts of street robberies as the outcome, the average out-of-sample mean squared prediction error of the baseline Poisson model was $72 \%$ of that of the linear model.

${ }^{9}$ In a 2 -fold cross-validation test using counts of street robberies as the outcome, the average out-of-sample mean squared prediction error of the negative binomial model was $103.5 \%$ of that of the baseline Poisson model. 
code to instrument for modern land use. There are a number of reasons why one might suspect that unobservable confounders or reverse causality between crime and land use are biasing the results obtained using the baseline approach. There is substantial evidence that crime rates are related to (difficult-to-measure) neighborhood social cohesion (Martin 2002, Morenoff, Sampson and Raudenbush 2001, Sampson, Raudenbush and Earls 1997). Homeowners have substantial incentives to exert control over changes in nearby land use patterns which may affect their property values (Fischel 2001). The extent to which they can do so depends on neighborhood social cohesion, since influencing the political process of zoning typically requires the concerted effort of many residents, which may be undermined by free-riding. Thus, neighborhood social cohesion may confound the relationship between land use patterns and crime.

Furthermore, reverse causality is potentially a concern because high levels of crime or rising crime rates may alter the incentives determining land use patterns. For example, crime may discourage the construction of new high-density residences, or it could lower property values, encouraging the encroachment of industrial or commercial uses into previously residential areas. It could also have the opposite effect, diminishing the incentives for new business formation. Rosenthal and Ross (2010) document precisely this kind of sorting behavior by entrepreneurs.

4.3.1. Instrument set. I include the percentage of each circle zoned for commercial and manufacturing use in 1923 as well as the percentage falling into volume districts 1, 2, and 3, with the omitted density category comprised of districts 4 and 5. The same variables are computed for the annulus around each circle. The square of each use variable is included, and each use variable is interacted with each density zoning variable. A quadratic in the distance to the nearest commercial and manufacturing zoning is included, and each distance is interacted with its circle's density zoning variables. Each circle use variable is interacted with each annulus use variable. 
4.3.2. Estimation. I estimate the model

$$
y_{i}=e^{x_{i}^{\prime} \beta}+u_{i}
$$

using generalized method of moments (GMM) (Hansen 1982). The moment conditions are

$$
\mathrm{E}\left[z_{i}\left(y_{i}-e^{x_{i}^{\prime} \beta}\right)\right]=0
$$

where $z_{i}$ includes the instruments discussed in section 4.3.1 as well as the covariates described in section 4.2, excluding the potentially-endogenous primary land use variables. In particular, the circle and annulus shares of single-family residential, commercial, and industrial uses are excluded, as is population density. The distances to the nearest commercial and industrial uses are omitted from $z_{i}$ as well. To obtain standard errors for the average marginal effects of interest, I use an $m$ out of $n$ without replacement bootstrap with 50 iterations and $\frac{m}{n} \approx \frac{1}{2}$. The $m$ out of $n$ without replacement bootstrap is known to be consistent under minimal assumptions (Bickel, Götze and van Zwet 1997, Politis and Romano 1994).

There are more moment conditions than parameters to estimate, so Hansen's $J$ statistic can be used to test the validity of the moment conditions (Hansen 1982). I find that I cannot reject the null hypothesis that the moment conditions are correctly specified for three of the six models I estimate. ${ }^{10}$ The $J$ statistic also provides further evidence that the exponential mean specification is superior to a simple linear model. ${ }^{11}$

4.3.3. Relevance. Table 1 presents the $F$ statistic and $R^{2}$ from a linear regression of each endogenous variable on the set of instruments outlined in section 4.3.1. It is clear that historical zoning is a strong predictor of modern land use, and in fact it explains much of the variation in present-day exposure to different use types.

However, in the case of multiple endogenous variables, the standard approach to measuring instrument strength is not sufficient. If there is insufficient variation in the instruments which

\footnotetext{
${ }^{10}$ The effectiveness of this test is questionable; the finite-sample size and power appear to be complex, nonlinear functions of the sample size, number of overidentifying restrictions, and instrument strength (Hansen, Heaton and Yaron 1996).

${ }^{11}$ GMM estimation of the robbery model on the full sample using the exponential mean specification yields a Hansen $J$ statistic of 87.36; the same estimation using a linear model yields a $J$ statistic of 161.98 .
} 
TABle 1. IV First Stage: Predicted Land Use Using Historical Zoning

\begin{tabular}{lcccc}
\hline & \multicolumn{2}{c}{ Circle } & \multicolumn{2}{c}{ Annulus } \\
\cline { 2 - 5 } Modern land use & $F$-statistic & $R^{2}$ & $F$-statistic & $R^{2}$ \\
\hline \% single-family housing & 325.492 & 0.392 & 514.797 & 0.505 \\
\% commercial & 330.164 & 0.395 & 229.447 & 0.312 \\
\% industrial & 183.142 & 0.266 & 303.275 & 0.375 \\
Distance to commercial use & 275.091 & 0.353 & & \\
Distance to industrial use & 1391.748 & 0.734 & & \\
\hline
\end{tabular}

\begin{tabular}{lcc}
\hline & \multicolumn{2}{c}{ Circle-annulus } \\
\cline { 2 - 3 } & $F$-statistic & $R^{2}$ \\
\hline Population $^{2}$ & 114.836 & 0.185 \\
Population $^{2}$ & 49.289 & 0.089 \\
Population $\times$ commercial & 35.611 & 0.066 \\
\hline
\end{tabular}

$1 \%$ critical value for the $F$-test: 1.60

Results from linear regressions of land use variables on the historical zoning instruments outlined in section 4.3.1. Regression $F$-statistics and $R^{2}$ are reported. Results for circle land uses are reported in the first two columns of the upper panel, while results for annulus land uses are reported in the second two columns. The bottom panel reports results for variables measured at the combined circle-annulus level. All models are estimated on the full sample.

can be uniquely attributed to each endogenous variable, then predicted values will be highly correlated and inferences will suffer. Currently, there is no test for weak instruments in nonlinear models with multiple endogenous variables. Shea (1997) describes a method for adjusting the first-stage $R^{2}$ in a linear IV model to account for the fact that the instruments are related to multiple correlated endogenous variables. I apply this linear approach here in lieu of a method appropriate for the nonlinear model I employ, since no such method is currently available.

Table 2 displays these partial $R^{2}$ values for each endogenous variable. While they are substantially smaller than the unadjusted $R^{2}$ in some cases, it is clear that near-perfect multicollinearity is not an issue. These partial $R^{2}$ are comparable to the first-stage $R^{2}$ in some other well-known studies using instrumental variables. ${ }^{12}$ As will be seen in section 5.2 ,

\footnotetext{
${ }^{12}$ The first-stage $R^{2}$ in the Levitt (1997) study on policing and crime ranges from 0.06 to 0.11 (see his table 2 ). The first-stage $R^{2}$ in the Angrist and Evans (1998) study on fertility and female labor supply ranges from 0.004 to 0.084 (see their table 6).
} 
TABLE 2. IV First Stage: Predicted Land Use Using Historical Zoning (Shea Method)

\begin{tabular}{lcc}
\hline & Circle & Annulus \\
\cline { 2 - 3 } Modern land use & Shea $R^{2}$ & Shea $R^{2}$ \\
\hline \% single-family housing & 0.032 & 0.033 \\
\% commercial & 0.066 & 0.052 \\
\% industrial & 0.036 & 0.044 \\
Distance to commercial use & 0.087 \\
Distance to industrial use & 0.345 \\
\hline & \multicolumn{2}{c}{ Circle-annulus } \\
\cline { 2 - 2 } & \multicolumn{2}{c}{ Shea $R^{2}$} \\
\hline Population & 0.018 \\
Population & \\
Population $\times$ \% commercial & 0.025 \\
\hline
\end{tabular}

Results from linear regressions of land use variables (orthogonalized to all other land use variables and covariates) on their predicted values using historical zoning instruments (orthogonalized from all other predicted values of land use variables using zoning instruments). The $R^{2}$ from these regressions describes the unique variation in each land use variable attributable to the instruments (Shea 1997). Results for circle land uses are reported in the first column of the upper panel, while results for annulus land uses are reported in the second column. The bottom panel reports results for variables measured at the combined circle-annulus level. All models are estimated on the full sample.

the standard errors increase when I move from the baseline approach to GMM, however they are not so large as to make inference impossible.

4.3.4. Exogeneity. The validity of the exclusion restriction implied by (4.3) hinges on the assumption that unobservable neighborhood characteristics which may have influenced crime and zoning in 1923 have not persisted to the present. In this section, I argue that large-scale demographic changes preclude this possibility, and I use historical data on crime, land use, and demographics to rigorously test for the persistence of criminogenic factors.

Substantial neighborhood transformation has taken place throughout Chicago over the past 90 years. The closure of the border following the 1921 Emergency Quota Act and the Immigration Act of 1924 led to the assimilation of the city's theretofore marginalized immigrant population. Deindustrialization and suburbanization following World War II caused a dramatic shift in the demographics of the city; Chicago lost nearly $22 \%$ of its population between 1960 and 1990 (Hunt and DeVries 2013). Bursik and Webb (1982) document that 
demographic changes in Chicago over the period 1940-1970 were strongly related to changes in delinquency, which is highly correlated with the serious crimes I consider. Many of the most segregated and violent enclaves today are located in outlying areas of the city that were largely inhabited by relatively high-status second-generation immigrants of western European descent in 1920 (Shertzer, Twinam and Walsh 2014a).

The unique range of data available for Chicago allows me to present some quantitative evidence of neighborhood change. As discussed in section 3.7, counts of homicides over the period 1870-1930 (largely concentrated between 1910 and 1930) are available for the 49 Chicago community areas that overlap my sample area. Homicide is a strong proxy for unmeasured neighborhood characteristics which may influence crime. If the factors that led to high crime in the early twentieth century are persistent, one would expect to find that historically high-crime areas continue to see a relatively high level of crime today. However, the correlation between historical and modern homicide counts is only -0.0465 .

Historical data on the percentage of families on public relief in 1934 is also available by community area. There is strong evidence suggesting that economic conditions influence crime by affecting individuals' incentives to offend (Becker 1968, Cantor and Land 1985, Fishback, Johnson and Kantor 2010). Historical public relief shares can be compared to modern public assistance shares derived from American Community Survey data (see sections 3.2 and 3.6). The correlation between historical and modern shares of households receiving public assistance is -0.0071 . These simple correlations suggest that the character of community areas in Chicago has changed dramatically.

The qualitative and quantitative evidence presented thus far suggests that unobservable neighborhood characteristics which may have influenced both zoning and crime in 1923 are unlikely to have persisted over the 90 years to the present. To further validate this supposition, I develop a rigorous test of the exclusion restriction utilizing the unique range of historical data available for Chicago.

Essentially, I argue that modern crime in my sample circles should only be related to historical crime to the extent that historical causes of crime have persisted to the present. 
Such causes include (measurable) land use patterns, zoning, and demographics as well as other (unmeasured) neighborhood characteristics. Thus, if historical crime is independent of modern crime, conditional on land use, zoning, and demographics, that strongly suggests that unobservable neighborhood characteristics that influenced crime in the past have not persisted to the present. This can be formalized most transparently using the language of causal graphical models; I relegate this discussion to a technical appendix.

Following this argument, I test for a relationship between historical and modern crime by estimating a Poisson regression of modern street homicide counts in my sample circles on historical homicide counts. I include only those historical homicides that can be geocoded to an exact street address. I also condition on the full set of zoning variables I use as instruments as well as historical land use data (attached to the circle as well as the associated annulus) and the 1920 population and share of the population that is black; this data is described in more detail in sections 3.4, 3.5, and 3.6. As a robustness check, I estimate the same model with street robberies as the outcome, since these are much more common and should allow for better inference. The results are given in table 3 .

TABle 3. Relationship Between Modern and Historical Crime

\begin{tabular}{lcc}
\hline & \# of modern homicides & \# of modern robberies \\
\cline { 2 - 3 } & $(1)$ & $(2)$ \\
\hline \multirow{2}{*}{ \# of historical homicides } & -.0002 & 0.0252 \\
& $(0.00436)$ & $(0.04032)$ \\
\hline Observations & 18,563 & 18,563
\end{tabular}

Results from Poisson regressions of street homicide or robbery counts on 1922 land use, 1920 population and racial composition, and 1923 zoning; see sections 3.5, 3.6, and 4.3.1 for details. Results are average marginal effects. Both models are estimated on the full sample, excluding some circles for which historical land use data is not available due to damaged land use maps. Robust standard errors are reported in parentheses.

In both specifications, the influence of historical homicides is very small and not statistically different from zero. This is strong evidence in favor of the identifying assumptions underlying my instrumental variable strategy. 
4.4. Identification: Spatial matching. In section 5.3, I test for the influence of specific commercial land uses (such as bars) on crime. Unfortunately, the instrumental variable strategy described above is not applicable here, since historical zoning can only predict general land use patterns and not specific commercial uses. I adopt an alternative approach, matching sample circles whose boundaries lie not more than 200 feet apart. I then analyze differences in outcomes between these matched observations as a function of differences in covariates. Assuming that unobservable neighborhood characteristics vary smoothly across space, they should be largely constant between matched observations, so that the effects of differences in land use can be identified.

I estimate models of the form

$$
y_{i}-y_{j}=\left(x_{i}-x_{j}\right)^{\prime} \beta+\epsilon_{i j}
$$

using ordinary least squares. Observations are paired so that the centroid of circle $i$ is within 500 feet of the centroid of circle $j$. The argument is that confounding factors will be differenced out; this should be the case if unobservable neighborhood characteristics which may influence crime vary smoothly across space. To gauge the effectiveness of this identification strategy, I use it to replicate the instrumental variables analysis. Estimation using OLS is arguably appropriate here since the estimated residuals are approximately normal. $^{13}$

\section{Results}

I first present descriptive statistics and discuss the spatial pattern of crime in Chicago. I then present results from baseline Poisson regressions without instruments in section 4.2. In section 5.2, I reestimate these models using GMM with historical zoning instruments. In section 5.3, I use the spatial matching approach to study the role of specific commercial land uses.

\footnotetext{
${ }^{13}$ The residuals display heavy tails due to the right-skewed distribution of crime. However, they are approximately normally distributed over most of the range of the differenced outcome variables.
} 
TABle 4. Descriptive Statistics: Outcomes

\begin{tabular}{lcc}
\hline & $(1)$ & $(2)$ \\
\hline \multirow{2}{*}{ Robberies } & 1.66 & 1.23 \\
& $(3.026)$ & $(1.720)$ \\
Robberies (per 1000 residents) & 2.56 & 1.37 \\
& $(6.919)$ & $(2.062)$ \\
Assaults & 1.24 & 1.14 \\
& $(2.010)$ & $(1.677)$ \\
Assaults (per 1000 residents) & 1.75 & 1.30 \\
& $(3.481)$ & $(2.056)$ \\
Batteries & 3.79 & 3.06 \\
& $(6.309)$ & $(4.255)$ \\
Batteries (per 1000 residents) & 5.54 & 3.55 \\
& $(11.392)$ & $(5.383)$ \\
\hline Observations & 18,712 & 9,125 \\
\hline Sample restrictions & None & Residential \\
\hline
\end{tabular}

Descriptive statistics on circle crime counts. In column (1), statistics for the entire sample are reported. In column (2), statistics are reported for circles that are exclusively residential.

Table 4 provides means and standard deviations of crime counts in my sample. Street crime in my data is highly concentrated spatially. The median number of street robberies is one, the median number of batteries is two, and the median number of assaults is one. $42 \%$ of observations see no robberies at all over the period 2008-2013; similarly, $29 \%$ see no batteries and $49 \%$ see no assaults. Sample points with four or more robberies, the top 13\%, account for $56 \%$ of the 31,131 robberies I observe. This is typical of urban crime and has been well documented elsewhere (Sherman et al. 1989, Weisburd et al. 2012).

Local and ambient commercial uses as well as population density are the primary predictors of interest in the baseline and instrumental variables analyses. Table 5 provides basic descriptive statistics for these variables. $21 \%$ of my sample points contain some commercial use, $10 \%$ contain some industrial use, and $49 \%$ are strictly residential. The average population in the combined circle-annulus area is 835, with an interquartile range of $[529,1091]$. The distribution of population is very similar for observations with and without any commercial uses.

In the matching analysis, I focus on specific commercial uses. In particular, I examine the effects of restaurants, bars, late-hour bars (those bars permitted to continue serving alcohol 
Table 5. Descriptive Statistics: Land Use

\begin{tabular}{lcc}
\hline & $(1)$ & $(2)$ \\
\hline \% commercial & 0.12 & \\
& $(0.27)$ & \\
\% ambient commercial & 0.12 & 0.09 \\
& $(0.14)$ & $(0.11)$ \\
Population density & 835.41 & 961.91 \\
& $(426.43)$ & $(390.31)$ \\
\hline Observations & 18,712 & 9,125 \\
\hline Sample restrictions & None & Residential \\
\hline
\end{tabular}

Descriptive statistics on circle and annulus commercial uses as well as population density. In column (1), statistics for the entire sample are reported. In column (2), statistics are reported for circles that are exclusively residential.

past 2 a.m.), and liquor stores. There are 8,426 matched pairs of circles in my sample. $9.5 \%$ of these pairs contain at least one restaurant, $2.5 \%$ contain at least one bar, and $2.4 \%$ contain at least one liquor store. Late-hour bars are considerably less common; only 40 pairs $(0.05 \%)$ contain at least one.

5.1. Baseline results. Columns (1)-(2) of table 6 report the baseline Poisson regression results for street robbery counts. Interpreting the magnitudes of the marginal effects of commercial and ambient commercial use requires some attention to the typical variation in these explanatory variables observed in the data. Since the circles are small and capture areas within opposing block faces, they are typically homogeneous, with half of the circles in my sample devoted exclusively to residential use. Circles that contain any commercial use are frequently dominated by such use. Thus, it is most natural to evaluate the impact of commercial use by considering the difference in crime between a fully-commercial and fully-residential circle. The variation in ambient commercial use is considerably less stark and its distribution is more effectively summarized by its standard deviation. The standard deviation of ambient commercial use is 0.14 , close to its mean of 0.12 , so scaling the average marginal effect by the standard deviation yields an effect similar to that of moving from a fully-residential annulus to one with the average level of ambient commercial use. 
TABle 6. Baseline Results: Street Crimes

\begin{tabular}{|c|c|c|c|c|c|c|}
\hline \multirow{2}{*}{ Land use } & \multicolumn{2}{|c|}{ \# of robberies } & \multicolumn{2}{|c|}{ \# of batteries } & \multicolumn{2}{|c|}{ \# of assaults } \\
\hline & (1) & $(2)$ & (3) & $(4)$ & $(5)$ & $(6)$ \\
\hline$\%$ commercial & $\begin{array}{c}0.508^{* * *} \\
(0.0780)\end{array}$ & & $\begin{array}{c}1.104^{* * *} \\
(0.170)\end{array}$ & & $\begin{array}{c}0.0822 \\
(0.0652)\end{array}$ & \\
\hline Ambient $\%$ commercial & $\begin{array}{c}1.141^{* * *} \\
(0.220)\end{array}$ & $\begin{array}{c}1.357^{* * *} \\
(0.208)\end{array}$ & $\begin{array}{c}3.100^{* * *} \\
(0.513)\end{array}$ & $\begin{array}{c}3.578^{* * *} \\
(0.465)\end{array}$ & $\begin{array}{c}1.129^{* * *} \\
(0.171)\end{array}$ & $\begin{array}{c}1.196^{* * *} \\
(0.248)\end{array}$ \\
\hline Population density & $\begin{array}{c}0.471^{* * *} \\
(0.0392)\end{array}$ & $\begin{array}{c}0.363^{* * *} \\
(0.0434)\end{array}$ & $\begin{array}{l}1.321^{* * *} \\
(0.0882)\end{array}$ & $\begin{array}{l}1.221^{* * *} \\
(0.0971)\end{array}$ & $\begin{array}{c}0.433^{* * *} \\
(0.0333)\end{array}$ & $\begin{array}{c}0.446^{* * *} \\
(0.0476)\end{array}$ \\
\hline $\begin{array}{l}\text { Population density } \\
\times \% \text { commercial }\end{array}$ & $\begin{array}{c}-0.105^{* *} \\
(0.0480)\end{array}$ & & $\begin{array}{c}0.580^{* * *} \\
(0.1122)\end{array}$ & & $\begin{array}{c}0.056 \\
(0.0426)\end{array}$ & \\
\hline Model & Poisson & Poisson & Poisson & Poisson & Poisson & Poisson \\
\hline Observations & 18,712 & 9,125 & 18,712 & 9,125 & 18,712 & 9,125 \\
\hline Sample restrictions & None & Residential & None & Residential & None & Residential \\
\hline
\end{tabular}

Results from baseline Poisson regressions of street robbery, battery, and assault counts on the full set of land use, demographic, and geographic covariates; see section 4.2 for details. Results are average marginal effects, and population density is standardized. For the interaction term, I report the estimate of $\mathrm{E}\left[\frac{\partial^{2} y}{\partial p o p \text { density } \partial \% \text { commercial }}\right]$, where $y$ is the outcome of interest. In odd-numbered columns, the model is estimated on the full sample. In even-numbered columns, the model is estimated only on circles that are exclusively residential. For the main effects, robust standard errors are reported in parentheses; for the interaction term, bootstrap standard errors are reported.

Fully-commercial circles are associated with 0.5 more street robberies than circles devoted exclusively to multi-family residential use. Since the median number of street robberies is one, this is a substantial difference. A one-standard-deviation increase in ambient commercial use is associated with 0.16 additional street robberies across the whole sample, and 0.15 additional street robberies on the subsample of strictly residential circles. A one-standarddeviation increase in population density is associated with 0.47 additional street robberies across the whole sample, and 0.36 additional robberies in the subsample of strictly residential circles.

The strong positive relationship between commercial uses and crime in their immediate vicinity is consistent with the existing literature. The variation in street robberies associated with differences in ambient commercial use is substantially smaller than that associated with immediately proximate commercial uses. This is an important fact that the previous 
literature has not been able to effectively document due to the sampling problems discussed in section 4.1. The relatively low spillover of crime from commercial areas to nearby residential areas has important policy implications, which I discuss in section 6 .

Columns (3)-(4) of table 6 report the baseline Poisson regression results for street battery counts. Fully-commercial circles are associated with 1.1 more street batteries than circles devoted exclusively to multi-family residential use; the median number of street batteries is two, so as is the case with street robberies, this is a substantial difference. A onestandard-deviation increase in ambient commercial use is associated with 0.43 additional street batteries across the whole sample, and 0.39 additional street batteries in the subsample of strictly residential circles. A one-standard-deviation increase in population density is associated with 1.3 additional street batteries across the whole sample, and 1.2 additional batteries in the subsample of strictly residential circles. In terms of its relation to land use, battery appears to behave much like robbery. Batteries are concentrated in the immediate vicinity of commercial uses with a smaller spillover effect into neighboring residential areas.

Columns (5)-(6) of table 6 report the baseline Poisson regression results for street assault counts. Fully-commercial circles are associated with 0.08 more street assaults than circles devoted exclusively to multi-family residential use, a small difference which is not statistically significantly different from zero. A one-standard-deviation increase in ambient commercial use is associated with 0.16 additional street assaults across the whole sample, and 0.13 additional street assaults in the subsample of strictly residential circles. These differences are statistically significantly different from zero but small relative to the median number of assaults, which is one. A one-standard-deviation increase in population density is associated with 0.43 additional street assaults across the whole sample, and 0.45 additional assaults in the subsample of strictly residential circles.

The spatial distribution of assaults clearly differs substantially from that of robberies and batteries. Assaults are not concentrated in the immediate proximity of commercial uses. They are more likely to be found in residential areas neighboring commercial uses, and the magnitude of this spillover effect is comparable to the estimates for robberies. This may be 
due to the hierarchical nature of incident reporting. Batteries are a class A misdemeanor in Illinois, so an incident involving an assault and a battery will be classified as a battery, since assaults are a (lower) class $\mathrm{C}$ misdemeanor. Thus, assaults refer to incidents that did not escalate to the level of a battery.

The population density results reported in table 6 consistently show that denser areas see a larger number of street robberies, batteries, and assaults. However, the difference is small when compared to the magnitude of a one-standard-deviation change in population density; the standard deviation of population density across the whole sample is 426 , and on the strictly residential subsample the standard deviation is 390 . Thus, it is likely that the additional 0.47 street robberies associated with a one-standard-deviation increase in population density are associated with a substantially lower risk of victimization. ${ }^{14}$ The predicted number of robberies for a circle with average population density is 1.77 (2.1 per 1000 residents), while it is 2.23 (1.8 per 1000 residents) for a circle with a population density one standard deviation above the mean. Similarly, the predicted number of batteries for a circle with average population density is 4.1 (4.9 per 1000 residents), while it is 5.5 (4.4 per 1000 residents) for a circle with a population density one standard deviation above the mean. Thus, population density has a negligible effect on counts of street crimes and higher populations are associated with substantially lower per capita crime rates.

The interaction between commercial use and residential density is of independent interest, as it conveys the impact of mixing residential and commercial uses. ${ }^{15}$ If the interaction is negative, one could argue that commercial uses accompanied by residences see less crime than standalone commercial uses. Returning to table 6 , it is clear that no consistent pattern

\footnotetext{
${ }^{14}$ Normalizing outcomes by population is unnecessary, as population density is accounted for in the model. Additionally, the per capita crime rate may not reflect the real crime rate at all; Balkin and McDonald (1981) show that, when potential victims respond rationally to the possibility of victimization, the probability of victimization per unit of exposure time (the real crime rate) may be inversely related to the per capita crime rate. Highly commercial areas may also see substantial pedestrian traffic from non-residents, so it is not clear how one would interpret results from a model with normalized outcomes.

${ }^{15}$ I report the estimated interaction between $\%$ commercial and population density; specifically, the average cross-partial derivative

$$
\mathrm{E}\left[\frac{\partial^{2} y}{\partial \text { popdensity } \partial \% \text { commercial }}\right]
$$

where $y$ is the outcome of interest.
} 
across crimes emerges. The interaction is negative and statistically significant for robbery counts. For battery counts, the interaction is positive and significant. The interaction is positive but statistically insignificant for assault counts.

In summary, the baseline results indicate a strong positive relationship between commercial uses and street robberies and batteries in their immediate vicinity; this relationship does not hold for assaults. For all three types of street crime, nearby commercial uses are associated with more crime in neighboring areas. Population density has a positive relationship with street crime counts, but this relationship is sufficiently weak that per capita crime rates fall with population density. No consistent relationship between street crime and the interaction of commercial uses and residential density emerges.

5.2. IV results. In this section, I reestimate the models from section 5.1 using GMM with historical zoning instruments for the potentially-endogenous land use variables. Columns (1)-(2) of table 7 report the IV results for street robbery counts. Fully-commercial circles are associated with 0.84 more street robberies than circles devoted exclusively to multifamily residential use. This estimate is substantially larger in magnitude that the baseline estimate, but also less precise. The IV estimates of the effect of ambient commercial use on the whole sample and the residential subsample are half the size of the corresponding baseline estimates. This suggests that the baseline approach is overestimating the spillover effect of commercial uses; however, the lack of precision in the estimates does not permit me to reject the hypothesis that these two marginal effects are equal. The IV estimates of the marginal effect of population density are slightly smaller than their baseline counterparts.

Columns (3)-(4) of table 7 report the IV results for street battery counts. As was the case for street robberies, the IV estimate of the marginal effect of commercial uses on crime in their immediate vicinity is larger than the baseline estimate. However, the marginal effects of ambient commercial use and population density are also larger than their associated baseline estimates, in most cases substantially larger. Columns (5)-(6) of table 7 report the IV results for street assault counts. The IV estimate of the marginal effect of commercial uses on crime in their immediate vicinity is still small and statistically insignificant. The marginal effects of 
TABle 7. IV Results: Street Crimes

\begin{tabular}{|c|c|c|c|c|c|c|}
\hline \multirow{2}{*}{ Land use } & \multicolumn{2}{|c|}{$\#$ of robberies } & \multicolumn{2}{|c|}{ \# of batteries } & \multicolumn{2}{|c|}{ \# of assaults } \\
\hline & $(1)$ & $(2)$ & $(3)$ & (4) & $(5)$ & (6) \\
\hline$\%$ commercial & $\begin{array}{c}0.836^{* * *} \\
(0.2537)\end{array}$ & & $\begin{array}{c}1.252^{* * *} \\
(0.432)\end{array}$ & & $\begin{array}{c}0.1645 \\
(0.1649)\end{array}$ & \\
\hline Ambient $\%$ commercial & $\begin{array}{c}0.467 \\
(1.041)\end{array}$ & $\begin{array}{c}0.758 \\
(0.8345)\end{array}$ & $\begin{array}{c}3.891^{* * *} \\
(1.511)\end{array}$ & $\begin{array}{l}5.887^{* * *} \\
(1.8902)\end{array}$ & $\begin{array}{c}1.804^{* * *} \\
(0.668)\end{array}$ & $\begin{array}{c}1.153 \\
(0.806)\end{array}$ \\
\hline Population density & $\begin{array}{c}0.368 \\
(0.2246)\end{array}$ & $\begin{array}{c}0.273 \\
(0.3422)\end{array}$ & $\begin{array}{r}2.256^{* * *} \\
(0.4686)\end{array}$ & $\begin{array}{l}2.206^{* * *} \\
(0.4811)\end{array}$ & $\begin{array}{c}0.686^{* * *} \\
(0.2147)\end{array}$ & $\begin{array}{c}0.212 \\
(0.191)\end{array}$ \\
\hline $\begin{array}{l}\text { Population density } \\
\times \% \text { commercial }\end{array}$ & $\begin{array}{l}-0.725^{*} \\
(0.4357)\end{array}$ & & $\begin{array}{c}-0.135 \\
(0.5852)\end{array}$ & & $\begin{array}{l}-0.392^{*} \\
(0.2168)\end{array}$ & \\
\hline Model & Poisson IV & Poisson IV & Poisson IV & Poisson IV & Poisson IV & Poisson IV \\
\hline Observations & 18,712 & 9,125 & 18,712 & 9,125 & 18,712 & 9,125 \\
\hline Sample restrictions & None & Residential & None & Residential & None & Residential \\
\hline & & $\begin{array}{l}\text { ndard error: } \\
\mathrm{p}<0.01, * *\end{array}$ & $\begin{array}{l}\mathrm{s} \text { in parenth } \\
\mathrm{p}<0.05,{ }^{*} \mathrm{p}\end{array}$ & & & \\
\hline
\end{tabular}

Results from GMM estimation of Poisson regressions of street robbery, battery, and assault counts on the full set of land use, demographic, and geographic covariates; see sections 4.2 and 4.3 .2 for details. Historical zoning variables are used as instruments for modern land use; see section 4.3.1 for details. Results are average marginal effects, and population density is standardized. For the interaction term, I report the estimate of $\mathrm{E}\left[\frac{\partial^{2} y}{\partial \text { popdensity } \partial \% \text { commercial }}\right]$, where $y$ is the outcome of interest. In odd-numbered columns, the model is estimated on the full sample. In even-numbered columns, the model is estimated only on circles that are exclusively residential. Bootstrap standard errors are reported in parentheses.

ambient commercial use are larger than their associated baseline estimates for the full sample and comparable for the residential subsample. As before, the marginal effect of population density is positive for all classes of crime. The IV estimates are smaller than the baseline estimates and not statistically significant for robberies, somewhat larger for batteries, and larger for assaults on the full sample but smaller on the residential subsample. Thus, the negative effect of population density on per capita robberies is strengthened here. Even for the largest estimate, batteries on the full sample, the effect of a one-standard-deviation increase in population density leaves the per capita battery rate unchanged.

Table 7 reports IV estimates of the interaction term between commercial use and population density. Unlike the mixed results obtained from the baseline regressions (reported in table 6), the IV estimates are consistently negative. For robbery and assault counts, the 
interaction is statistically different from zero. These findings are consistent with those of Anderson et al. (2013), who find that mixed use blocks see less crime than strictly commercial blocks. ${ }^{16}$

In summary, the IV results show a strong positive effect of commercial uses on street robberies and batteries in their immediate vicinity, but no effect on assaults. The IV estimates of the spillover effects of commercial uses are larger than the baseline estimates for batteries, but smaller than the baseline estimates for robberies and assaults; however, these effects are estimated much less precisely, so it is difficult to draw firm conclusions. It can be said that the typical spillover effect is small (but nontrivial) relative to the direct effect of moving to a fully-residential to a fully-commercial circle. As before, population density has a weak positive effect on street crime counts, but a negative or zero effect on crimes per capita. Unlike the baseline case, the IV estimates of the interaction between commercial uses and population density are consistently negative and, for robberies and assaults, statistically different from zero.

5.3. Spatial matching results. The baseline results establish that robberies, batteries and assaults are spatially concentrated near commercial uses. The IV estimates argue that this relationship is causal. In this section, I replicate the analysis of robberies, batteries, and assaults using the spatial matching approach described in section 4.4. I then use this approach to measure the criminogenic effects of restaurants, (late-hour) bars, and liquor stores as well as the "residual" effect of general commercial activity after accounting for these uses.

Observable neighborhood characteristics vary smoothly over space, so the spatial matching approach employed here yields matched pairs nearly identical in observable characteristics. The average difference in population between matched observations is 1 person, and the standard deviation of the difference is 181 persons. This is small relative to the average

\footnotetext{
${ }^{16}$ This interaction would not represent the hypothesized relationship between residential density and commercial uses if certain particularly criminogenic land uses (such as bars or liquor stores) were less likely to appear in mixed-use structures. However, I find a weak positive correlation between this interaction and counts of bars, late-hour bars, and liquor stores, so this concern is unwarranted; these estimates may in fact be biased towards zero.
} 
TABLE 8. Matching Results: Robbery

\begin{tabular}{|c|c|c|c|c|}
\hline \multirow{3}{*}{ Land use } & \multicolumn{4}{|c|}{ Outcome } \\
\hline & \multicolumn{4}{|c|}{ \# of robberies } \\
\hline & (1) & $(2)$ & $(3)$ & $(4)$ \\
\hline$\%$ commercial & $\begin{array}{c}1.400^{* * *} \\
(0.215)\end{array}$ & $\begin{array}{c}0.808^{* * *} \\
(0.251)\end{array}$ & & \\
\hline Ambient $\%$ commercial & $\begin{array}{c}0.260 \\
(0.697)\end{array}$ & $\begin{array}{r}-0.0111 \\
(0.813)\end{array}$ & $\begin{array}{l}-0.303 \\
(0.720)\end{array}$ & $\begin{array}{c}-0.0308 \\
(0.834)\end{array}$ \\
\hline Population density & $\begin{array}{l}0.214^{*} \\
(0.123)\end{array}$ & $\begin{array}{c}0.194 \\
(0.125)\end{array}$ & $\begin{array}{c}0.106 \\
(0.176)\end{array}$ & $\begin{array}{c}0.101 \\
(0.178)\end{array}$ \\
\hline \# of restaurants & & $\begin{array}{c}0.155^{* * *} \\
(0.0484)\end{array}$ & & \\
\hline \# of bars & & $\begin{array}{c}0.157 \\
(0.233)\end{array}$ & & \\
\hline \# of late-hour bars & & $\begin{array}{l}1.432^{*} \\
(0.847)\end{array}$ & & \\
\hline \# of liquor stores & & $\begin{array}{c}1.252^{* * *} \\
(0.358)\end{array}$ & & \\
\hline \# of nearby restaurants & & $\begin{array}{l}0.00681 \\
(0.0135)\end{array}$ & & $\begin{array}{l}-0.0183 \\
(0.0141)\end{array}$ \\
\hline \# of nearby bars & & $\begin{array}{c}0.0783 \\
(0.0593)\end{array}$ & & $\begin{array}{l}0.135^{* *} \\
(0.0601)\end{array}$ \\
\hline \# of nearby late-hour bars & & $\begin{array}{c}-0.0781 \\
(0.221)\end{array}$ & & $\begin{array}{r}-0.0992 \\
(0.256)\end{array}$ \\
\hline \# of nearby liquor stores & & $\begin{array}{l}0.00765 \\
(0.0845)\end{array}$ & & $\begin{array}{l}-0.0301 \\
(0.0808)\end{array}$ \\
\hline Model & OLS & OLS & OLS & OLS \\
\hline Observations & 8,414 & 8,414 & 2,843 & 2,843 \\
\hline Sample restrictions & None & None & Residential & Residential \\
\hline $\begin{array}{l}\text { Stan } \\
* * * \mathrm{p}\end{array}$ & $\begin{array}{l}\text { ard error } \\
0.01, * *\end{array}$ & $\begin{array}{l}\text { a parenth } \\
0.05,{ }^{*} \mathrm{p}\end{array}$ & & \\
\hline
\end{tabular}

Results from linear regressions of street robbery counts on the full set of land use, demographic, and geographic covariates; see section 4.2 for details. Variables used in estimating (1)-(4) are differences across matched pairs of observations; see section 4.4 for details. Columns (2) and (4) include 8 additional variables measuring differences in counts of restaurants, bars, late-hour bars, and liquor stores across both circles and annuluses. In columns (1) and (3), the models are estimated on the full sample of matched pairs. In columns (2) and (4), the models are estimated using only the matched pairs whose circles are exclusively residential. Robust standard errors are reported in parentheses.

population (844 persons) and the standard deviation of population (419 persons). The average difference in the percentage of residents that are black (Hispanic) between matched observations is $0.03(0.01)$ percentage points and the standard deviation of the difference is 4.97 (4.35) percentage points. The average difference in the percentage of households that 
are owner occupied is 0.06 percentage points, with a standard deviation of 6.39 percentage points.

TABLE 9. Matching Results: Battery

\begin{tabular}{|c|c|c|c|c|}
\hline \multirow{3}{*}{ Land use } & \multicolumn{4}{|c|}{ Outcome } \\
\hline & \multicolumn{4}{|c|}{ \# of batteries } \\
\hline & $(1)$ & $(2)$ & $(3)$ & $(4)$ \\
\hline$\%$ commercial & $\begin{array}{c}3.158^{* * *} \\
(0.419)\end{array}$ & $\begin{array}{c}0.470 \\
(0.446)\end{array}$ & & \\
\hline Ambient $\%$ commercial & $\begin{array}{c}2.982^{* *} \\
(1.274)\end{array}$ & $\begin{array}{c}1.085 \\
(1.427)\end{array}$ & $\begin{array}{c}4.378^{* * *} \\
(1.566)\end{array}$ & $\begin{array}{c}3.609^{* *} \\
(1.767)\end{array}$ \\
\hline Population density & $\begin{array}{c}1.125^{* * *} \\
(0.264)\end{array}$ & $\begin{array}{c}1.015^{* * *} \\
(0.257)\end{array}$ & $\begin{array}{c}1.223^{* * *} \\
(0.420)\end{array}$ & $\begin{array}{c}1.283^{* * *} \\
(0.427)\end{array}$ \\
\hline \# of restaurants & & $\begin{array}{c}0.726^{* * *} \\
(0.109)\end{array}$ & & \\
\hline \# of bars & & $\begin{array}{c}2.004^{* * *} \\
(0.480)\end{array}$ & & \\
\hline \# of late-hour bars & & $\begin{array}{c}10.17^{* * *} \\
(3.068)\end{array}$ & & \\
\hline \# of liquor stores & & $\begin{array}{c}4.114^{* * *} \\
(0.613)\end{array}$ & & \\
\hline \# of nearby restaurants & & $\begin{array}{c}0.0781^{* * *} \\
(0.0229)\end{array}$ & & $\begin{array}{c}0.0593^{* *} \\
(0.0266)\end{array}$ \\
\hline \# of nearby bars & & $\begin{array}{c}0.172 \\
(0.114)\end{array}$ & & $\begin{array}{c}-0.0640 \\
(0.114)\end{array}$ \\
\hline \# of nearby late-hour bars & & $\begin{array}{l}-0.583 \\
(0.467)\end{array}$ & & $\begin{array}{l}-0.354 \\
(0.341)\end{array}$ \\
\hline \# of nearby liquor stores & & $\begin{array}{c}-0.000111 \\
(0.142)\end{array}$ & & $\begin{array}{l}-0.191 \\
(0.164)\end{array}$ \\
\hline Model & OLS & OLS & OLS & OLS \\
\hline Observations & 8,414 & 8,414 & 2,843 & 2,843 \\
\hline Sample restrictions & None & None & Residential & Residential \\
\hline
\end{tabular}

Results from linear regressions of street battery counts on the full set of land use, demographic, and geographic covariates; see section 4.2 for details. Variables used in estimating (1)-(4) are differences across matched pairs of observations; see section 4.4 for details. Columns (2) and (4) include 8 additional variables measuring differences in counts of restaurants, bars, late-hour bars, and liquor stores across both circles and annuluses. In columns (1) and (3), the models are estimated on the full sample of matched pairs. In columns (2) and (4), the models are estimated using only the matched pairs whose circles are exclusively residential. Robust standard errors are reported in parentheses.

Columns (1) and (3) of tables 8-10 present estimates of the robbery, battery, and assault results from table 6 using the spatial matching approach. A comparison of these results 
with the IV estimates is illuminating. The matching estimates of the impacts of commercial uses are larger than the IV estimates for all three classes of street crime. The matching estimates of the impacts of ambient commercial uses and population density on robberies are smaller than the corresponding IV estimates, but the differences are not statistically significant. The estimated effects of ambient commercial uses and population density on batteries and assaults are generally larger than the IV estimates, but these differences are also largely insignificant. The results are consistent with large effects of commercial uses in their immediate vicinity but smaller (and, in the case of robberies, negligible) spillover effects into neighboring areas. The matching results further indicate that population density has a small impact on street crime. The close relationship between the IV and matching results lends credence to the underlying identifying assumptions.

Moving on to the analysis of individual uses, column (2) of table 8 presents estimates from the street robbery model with the addition of differences in counts of restaurants, bars, late-hour bars, and liquor stores in each circle as well as each annulus. Column (4) limits the sample to strictly residential circles, so only the annulus differences are included. An additional restaurant or bar in a circle leads to an additional 0.16 robberies; only for restaurants is this coefficient statistically significant. Late-hour bars are those bars permitted to continue serving alcohol past 2 a.m.; an additional late-hour bar leads to 1.43 additional robberies, a very sizable effect. An additional liquor store also has a sizable effect, leading to 1.25 additional robberies. The results are similar for batteries and assaults: Late-hour bars and liquor stores have an outsized effect, while bars and restaurants have a positive but substantially smaller impact. The existing empirical literature has focused on the role of bars as crime generators and attractors; the fact that liquor stores have a much larger impact has not been recognized. The large difference in impact between bars that close at 2 a.m. and those that stay open late is striking and has not been documented previously.

Because I account for general commercial use in these regressions, I can estimate the extent to which the positive effect of commercial uses on crime is driven by the specific uses I consider. Column (2) of table 8 shows that even after accounting for uses that attract a 
TABLE 10. Matching Results: Assault

\begin{tabular}{|c|c|c|c|c|}
\hline \multirow{3}{*}{ Land use } & \multicolumn{4}{|c|}{ Outcome } \\
\hline & \multicolumn{4}{|c|}{ \# of assaults } \\
\hline & (1) & $(2)$ & $(3)$ & $(4)$ \\
\hline$\%$ commercial & $\begin{array}{c}0.410^{* * *} \\
(0.142)\end{array}$ & $\begin{array}{l}-0.248 \\
(0.154)\end{array}$ & & \\
\hline Ambient $\%$ commercial & $\begin{array}{c}1.156^{* *} \\
(0.463)\end{array}$ & $\begin{array}{l}1.018^{*} \\
(0.534)\end{array}$ & $\begin{array}{c}1.907^{* * *} \\
(0.724)\end{array}$ & $\begin{array}{c}2.464^{* * *} \\
(0.861)\end{array}$ \\
\hline Population density & $\begin{array}{c}0.239^{* *} \\
(0.118)\end{array}$ & $\begin{array}{c}0.220^{*} \\
(0.116)\end{array}$ & $\begin{array}{c}0.379^{*} \\
(0.220)\end{array}$ & $\begin{array}{c}0.423^{*} \\
(0.222)\end{array}$ \\
\hline \# of restaurants & & $\begin{array}{c}0.215^{* * *} \\
(0.0297)\end{array}$ & & \\
\hline \# of bars & & $\begin{array}{c}0.372^{* * *} \\
(0.138)\end{array}$ & & \\
\hline \# of late-hour bars & & $\begin{array}{c}1.360^{* * *} \\
(0.469)\end{array}$ & & \\
\hline \# of liquor stores & & $\begin{array}{c}0.770^{* * *} \\
(0.174)\end{array}$ & & \\
\hline \# of nearby restaurants & & $\begin{array}{c}0.00580 \\
(0.00773)\end{array}$ & & $\begin{array}{r}-0.00249 \\
(0.0117)\end{array}$ \\
\hline \# of nearby bars & & $\begin{array}{l}-0.0219 \\
(0.0412)\end{array}$ & & $\begin{array}{l}-0.102^{*} \\
(0.0597)\end{array}$ \\
\hline \# of nearby late-hour bars & & $\begin{array}{l}-0.115 \\
(0.117)\end{array}$ & & $\begin{array}{c}-0.451^{* * *} \\
(0.174)\end{array}$ \\
\hline \# of nearby liquor stores & & $\begin{array}{c}0.0411 \\
(0.0481) \\
\end{array}$ & & $\begin{array}{l}-0.0199 \\
(0.0671)\end{array}$ \\
\hline Model & OLS & OLS & OLS & OLS \\
\hline Observations & 8,414 & 8,414 & 2,843 & 2,843 \\
\hline Sample restrictions & None & None & Residential & Residential \\
\hline $\begin{array}{l}\text { Stan } \\
* * * \mathrm{p}\end{array}$ & $\begin{array}{l}\text { ard error } \\
0.01, * *\end{array}$ & $\begin{array}{l}\mathrm{n} \text { parenth } \\
0.05, * \mathrm{p}\end{array}$ & & \\
\hline
\end{tabular}

Results from linear regressions of street assault counts on the full set of land use, demographic, and geographic covariates; see section 4.2 for details. Variables used in estimating (1)-(4) are differences across matched pairs of observations; see section 4.4 for details. Columns (2) and (4) include 8 additional variables measuring differences in counts of restaurants, bars, late-hour bars, and liquor stores across both circles and annuluses. In columns (1) and (3), the models are estimated on the full sample of matched pairs. In columns (2) and (4), the models are estimated using only the matched pairs whose circles are exclusively residential. Robust standard errors are reported in parentheses.

substantial amount of crime, other commercial uses have a sizable effect on robberies; more than half of the estimated commercial effect is due to uses other than restaurants, (latehour) bars, and liquor stores. This not the case for batteries and assaults; after accounting for specific uses, the commercial effect is small and statistically insignificant for these crimes. 
Previous studies that examined the effects of specific uses did not exhaustively account for all uses and did not include any controls for general commercial use, so they were unable to estimate this residual effect or disentangle the impact of specific uses from the fact that such uses are naturally located in commercial areas. My finding that commercial areas lead to robberies even in the absence of particularly criminogenic uses (such as bars and liquor stores) constitutes an important result, and the contrasting finding that batteries and assaults are driven by particular uses is striking as well.

The annulus use results in columns (2) and (4) of table 8 indicate that restaurants, (latehour) bars, and liquor stores all have a negligible effect on robberies in nearby areas; their effects are restricted to the immediate area surrounding the establishment. The same pattern holds for batteries and assaults.

\section{Discussion And POLICY implications}

My results indicate that commercial uses lead to substantially more street robberies and batteries in their immediate vicinity. The spillover effect into neighboring areas is relatively small for robberies but more substantial for batteries and assaults; the ability to measure this spillover is a novel feature of my approach to defining units of observation. Liquor stores and late-hour bars have large positive impacts on street robberies, while restaurants and bars have smaller but still nontrivial positive effects. The prominence of liquor stores over bars as crime generators/attractors is striking given the common perception of bars as hot spots of crime. Even after accounting for these uses, there is a large residual impact of general commercial use on robberies, which has not been documented previously due to data limitations. In contrast, the effect of commercial uses on batteries and assaults is almost entirely driven by the four specific uses I consider; restaurants and bars have moderatelysized effects while liquor stores and especially late-hour bars have dramatic effects in their immediate vicinity. The agreement between the IV and matching analyses on the effects of local and ambient commercial use lends considerable credibility to my conclusions; these 
results are unlikely to be driven by unobservable neighborhood characteristics or reverse causality.

My results are a partial vindication of the hypothesized relationship between land use and crime suggested by Jacobs (1961). Contra Jacobs, commercial uses attract a substantial amount of crime, and this relationship is particularly strong for commercial activities that generate pedestrian traffic throughout the day. However, this effect is ameliorated by higher residential densities, suggesting that mixed uses attract less crime than exclusively commercial uses. This fact is only revealed in the instrumental variable analysis, further highlighting the importance of my identification strategy. Higher densities also result in lower per capita crime rates, which is consistent with the views of Glaeser (2011). This suggests that land use regulations which favor higher residential density could improve neighborhood safety, and that zoning which allows for mixed use structures may be preferable to more restrictive rules that aim for exclusively commercial use.

Crime aside, proximity to commercial activity is desirable for a number of reasons, so it is worth considering methods of mitigating its criminogenic externalities. There is some evidence that the establishment of business improvement districts, where businesses pool resources to provide for additional local security, leads to substantial reductions in crime (Brooks 2008, Cook and MacDonald 2011). There is considerable evidence that the particular strategies employed by the police are an important determinant of their success in combating crime (Braga and Weisburd 2010). As discussed previously, crime is highly concentrated spatially, and this concentration is generally stable over time (Weisburd et al. 2012). Numerous strategies have been devised which focus police attention on these crime hot spots, including directed patrol and problem-oriented policing. There is a large experimental literature evaluating the impacts of these interventions, measuring their effects on crime and community relations as well as the extent to which they result in displacement, i.e., the shifting of crime to nearby areas not targeted by the intervention (Braga 2005). This literature convincingly demonstrates that intensive and problem-oriented policing applied to crime hot spots can result in sizable reductions in violent street crime without displacing 
crime to nearby areas or straining the relationship between police and the community (Braga and Bond 2008, Braga, Weisburd, Waring, Mazerolle, Spelman and Gajewski 1999, Sherman and Rogan 1995).

The findings of this literature suggest that crime concentrations resulting from specific uses (like liquor stores and late-hour bars) could be partially mitigated by strategic applications of police resources. However, such resources are costly. Zoning is a powerful and flexible tool for controlling land use patterns. It could potentially be employed to constrain the number and diffusion of such uses, limiting the strain they impose on police resources.

Future work should focus on the sources of heterogeneity in the extent to which commercial uses drive local crime; why do some commercial areas become crime hot spots while others do not? The distinction between attracting and generating crime is important as well. If commercial uses merely attract a finite local supply of potential offenders, an increase in the amount of commercial activity in an area may affect the spatial distribution of crime but leave the total amount of crime unchanged. Closely related to this is the question of how the extent to which commercial uses are concentrated or diffuse influences the overall crime rate. Jacobs (1961) argues that diffusing commercial uses results in less crime, while criminology research on offender behavior would suggest the opposite (Bernasco and Block 2009, Wright and Decker 1997). I am exploring this question in ongoing research.

\section{DATA APPENDiX}

Establishments with a "Retail Food Establishment" license are classified as restaurants, unless they also have a "Tavern" license, "Packaged Goods" (retail liquor) license, or "Tobacco Retail Over Counter" license. This category includes restaurants that serve alcohol. Such establishments will also have a "Consumption on Premises - Incidental Activity" license; this allows me to distinguish restaurants that serve alcohol from bars that serve food. I also classify businesses as restaurants if they have a "Retail Food Establishment" license as well as both a "Tobacco Retail Over Counter" and "Consumption on Premises - Incidental Activity" license; this combination is generally associated with restaurants, while the 
combination of "Retail Food Establishment" and "Tobacco Retail Over Counter" without a "Consumption on Premises - Incidental Activity" license is generally associated with grocery stores. Businesses with a "Tavern" license are classified as bars, unless they also have a "Late Hour" license. This secondary license allows bars to continue serving alcohol past the legal closing time of 2 a.m.; I refer to these bars as late-hour bars and treat them separately in my analysis. Establishments with a "Packaged Goods" license are permitted to sell liquor in manufacturer-sealed containers. I classify these establishments as liquor stores unless they also have a "Retail Food Establishment," "Tavern," or "Late Hour" license.

\section{TECHniCAL APPEndiX}

In this section, I discuss the theoretical justification for the exogeneity test proposed in section 4.3.4. Intuitively, I argue that historical crime should only be related to modern crime to the extent that historical causes of crime have persisted to the present. Such causes include (measurable) land use patterns, zoning, and demographics as well as other (unmeasured) neighborhood characteristics. Thus, if historical crime is independent of modern crime, conditional on historical land use, zoning, and demographics, that strongly suggests that unobservable neighborhood characteristics which influenced crime in the past have not persisted to the present. A causal graphical model provides a convenient and compact way to formalize and visualize this argument.

Figure 5 illustrates the basic identification problem: The effect of modern land use $L_{M}$ on modern crime $C_{M}$ is confounded by unobservable neighborhood characteristics $U_{M}$. This is a causal graphical model, which encodes conditional (in)dependences implied by a full nonparametric structural equation model (Pearl 2009). Arrows can be read as directional causal statements, so that $L_{M}$ has a causal effect on $C_{M}$, and $U_{M}$ has a causal effect on both. Grey nodes denote observable variables while white nodes denote unobservable variables; for readability, and without loss of generality, I present certain categories of related variables as a single node. 


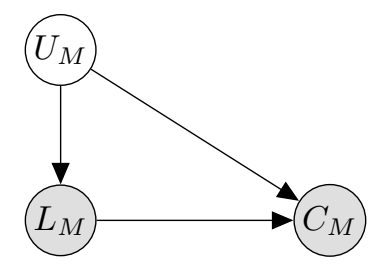

FIGURE 5

A solution to the implied identification problem is the introduction of historical zoning $Z_{H}$ as an instrumental variable (figure 6 ). If $Z_{H}$ is unconditionally independent of $U_{M}$, i.e., if the dashed link between historical unobservable neighborhood characteristics $U_{H}$ and its modern counterpart $U_{M}$ is absent (so that unobservable neighborhood characteristics are not persistent), then the effect of land use on crime can be identified. ${ }^{17}$ However, if this link is present, the instrument is contaminated and it is likely that the exclusion restriction does not hold.

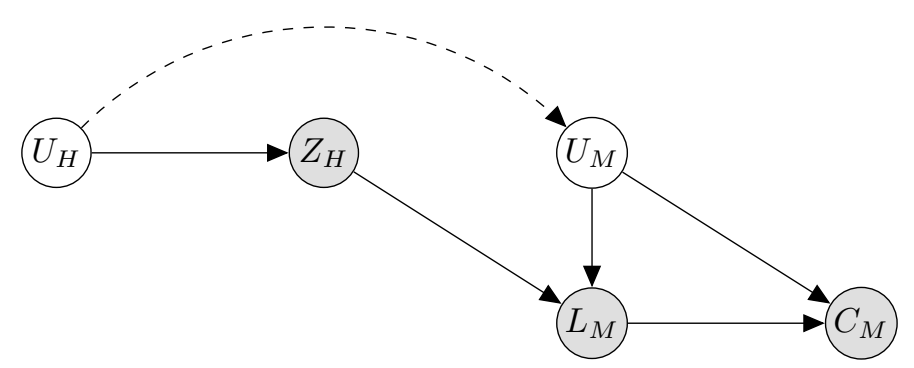

FigURE 6

The unique data available for Chicago allows for a strong test of this independence assumption. Figure 7 shows how the zoning variable $Z_{H}$ is embedded in an analogous historical version of figure 5 . The availability of geocoded historical land use, demographic, and homicide data (described in sections 3.5, 3.6, and 3.7) means that the historical analogs of $L_{M}$ and $C_{M}, L_{H}$ and $C_{H}$, can be observed. From the graph, one can deduce that $C_{H}$ is independent of $C_{M}$ conditional on $Z_{H}$ and $L_{H}$ if $U_{H}$ is unconditionally independent of $U_{M}$, i.e., if the dashed link is absent. ${ }^{18}$ In the language of Pearl (2009), $Z_{H}$ and $L_{H} \mathrm{~d}$-separate $C_{H}$ and $C_{M}$

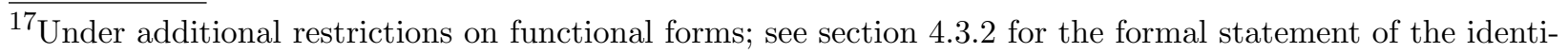
fying assumptions.

${ }^{18}$ The graph must be correctly specified for this statement to hold, however my argument is robust to a variety of changes in graph structure. Including an arrow between $Z_{H}$ and $C_{H}$ (regardless of orientation) or reversing the orientation of the arrow between $L_{H}$ and $C_{H}$ or $L_{H}$ and $U_{H}$ does not affect my argument. 
when $U_{H}$ is unconditionally independent of $U_{M}$. This suggests that testing for a relationship between historical and modern crime will provide a test of the IV exclusion restriction. $C_{H}$ may be uncorrelated with $C_{M}$ conditional on $Z_{H}$ and $L_{H}$ even if the dashed link in figure 6 is present, however this would require a level of fine-tuning that seems unlikely to occur in practice.

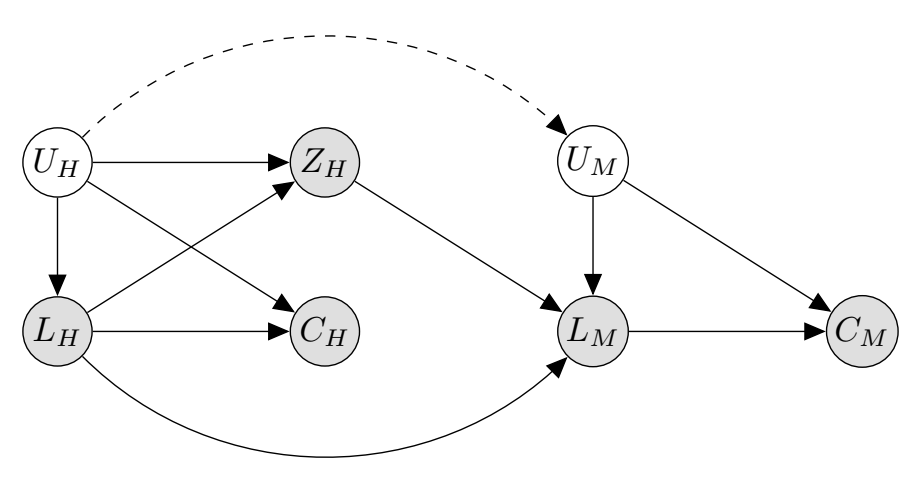

FiguRe 7

\section{REFERENCES}

Anderson, James M., John M. MacDonald, Ricky Bluthenthal, and J. Scott Ashwood (2013). Reducing crime by shaping the built environment with zoning: An empirical study of Los Angeles. University of Pennsylvania Law Review, 161, pp. 699-861.

Angrist, Joshua D. and William N. Evans (1998). Children and their parents labor supply: Evidence from exogenous variation in family size. American Economic Review, 88(3), pp. 450-477.

Balkin, Steven and John F. McDonald (1981). The market for street crime: An economic analysis of victim-offender interaction. Journal of Urban Economics, 10(3), pp. 390-405.

Becker, Gary S. (1968). Crime and punishment: An economic approach. Journal of Political Economy, 76(2), pp. 169-217.

Bernasco, Wim and Richard Block (2009). Where offenders choose to attack: A discrete choice model of robberies in Chicago. Criminology, 47(1), pp. 93-130.

(2011). Robberies in Chicago: A block-level analysis of the influence of crime generators, crime attractors, and offender anchor points. Journal of Research in Crime and Delinquency, 48(1), pp. 33-57.

Bickel, P.J., F. Götze, and W.R. van Zwet (1997). Resampling fewer than $n$ observations: Gains, losses, and remedies for losses. Statistica Sinica, 7, pp. 1-31.

Bienen, Leigh B. and Brandon Rottinghaus (2002). Learning from the past, living in the present: Understanding homicide in Chicago, 1870-1930. Journal of Criminal Law and Criminology, 92(3), p. 437.

Blackburn, McKinley L. (2014). The relative performance of Poisson and negative binomial regression estimators. Oxford Bulletin of Economics and Statistics, forthcoming. 
Bradbury, Katharine L., Anthony Downs, and Kenneth A. Small (1982). Urban decline and the future of American cities. Brookings Institution.

Braga, Anthony A. (2005). Hot spots policing and crime prevention: A systematic review of randomized controlled trials. Journal of Experimental Criminology, 1(3), pp. 317-342.

Braga, Anthony A. and Brenda J. Bond (2008). Policing crime and disorder hot spots: A randomized controlled trial. Criminology, 46(3), pp. 577-607.

Braga, Anthony A. and David L. Weisburd (2010). Policing problem places. Oxford University Press.

Braga, Anthony A., Andrew V. Papachristos, and David M. Hureau (2010). The concentration and stability of gun violence at micro places in Boston, 1980-2008. Journal of Quantitative Criminology, 26(1), pp. 33-53.

Braga, Anthony A., David L. Weisburd, Elin J. Waring, Lorraine G. Mazerolle, William Spelman, and Francis Gajewski (1999). Problem-oriented policing in violent crime places: A randomized controlled experiment. Criminology, 37(3), pp. 541-580.

Brooks, Leah (2008). Volunteering to be taxed: Business improvement districts and the extra-governmental provision of public safety. Journal of Public Economics, 92(1), pp. 388-406.

Browning, Christopher R., Reginald A. Byron, Catherine A. Calder, Lauren J. Krivo, Mei-Po Kwan, Jae-Yong Lee, and Ruth D. Peterson (2010). Commercial density, residential concentration, and crime: Land use patterns and violence in neighborhood context. Journal of Research in Crime and Delinquency, 47(3), pp. 329-357.

Bulmer, Martin (1986). The Chicago school of sociology: Institutionalization, diversity, and the rise of sociological research. University of Chicago Press.

Bursik, Robert J. and Jim Webb (1982). Community change and patterns of delinquency. American Journal of Sociology, 88(1), pp. 24-42.

Cameron, A. Colin and Pravin K. Trivedi (2013). Regression analysis of count data. Cambridge University Press.

Cantor, David and Kenneth C. Land (1985). Unemployment and crime rates in the postWorld War II United States: A theoretical and empirical analysis. American Sociological Review, 50(3), pp. 317-332.

Carter, Sherry P., Stanley L. Carter, and Andrew L. Dannenberg (2003). Zoning out crime and improving community health in Sarasota, Florida: "Crime prevention through environmental design". American Journal of Public Health, 93(9), pp. 1442-1445.

Cohen, Lawrence E. and Marcus Felson (1979). Social change and crime rate trends: A routine activity approach. American Sociological Review, 44(4), pp. 588-608.

Conley, Timothy G. (1999). GMM estimation with cross sectional dependence. Journal of Econometrics, 92(1), pp. 1-45.

Cook, Philip J. and John MacDonald (2011). Public safety through private action: An economic assessment of BIDs. Economic Journal, 121(552), pp. 445-462.

Coupland, Andy (1997). Reclaiming the city: Mixed use development. Taylor \& Francis.

Cui, Lin and Randall Walsh (2014). Foreclosure, vacancy and crime. SSRN Working Paper \#1773706.

Cullen, Julie Berry and Steven D. Levitt (1999). Crime, urban flight, and the consequences for cities. Review of Economics and Statistics, 81(2), pp. 159-169.

Fischel, William A. (2001). The homevoter hypothesis. Harvard University Press. 
Fishback, Price V., Ryan S. Johnson, and Shawn Kantor (2010). Striking at the roots of crime: The impact of welfare spending on crime during the Great Depression. Journal of Law and Economics, 53(4), pp. 715-740.

Glaeser, Edward (2011). Triumph of the city: How our greatest invention makes us richer, smarter, greener, healthier and happier. Penguin Press.

Gourieroux, Christian S., Alain Monfort, and Alain Trognon (1984a). Pseudo maximum likelihood methods: Applications to Poisson models. Econometrica, 52(3), pp. 701-20. (1984b). Pseudo maximum likelihood methods: Theory. Econometrica, 52(3), pp. $681-700$.

Hansen, Lars Peter (1982). Large sample properties of generalized method of moments estimators. Econometrica, 50(4), pp. 1029-54.

Hansen, Lars Peter, John Heaton, and Amir Yaron (1996). Finite-sample properties of some alternative GMM estimators. Journal of Business 85 Economic Statistics, 14(3), pp. 262280.

Hunt, D. Bradford and Jon B. DeVries (2013). Planning Chicago. American Planning Association Planners Press.

Jacobs, Jane (1961). The death and life of great American cities. Random House.

Levitt, Steven D. (1997). Using electoral cycles in police hiring to estimate the effect of police on crime. American Economic Review, 87(3), pp. 270-290.

Loukaitou-Sideris, Anastasia (1999). Hot spots of bus stop crime: The importance of environmental attributes. Journal of the American Planning Association, 65(4), pp. 395-411.

Martin, David (2002). Spatial patterns in residential burglary Assessing the effect of neighborhood social capital. Journal of Contemporary Criminal Justice, 18(2), pp. 132-146.

Massey, Douglas S. and Nancy A. Denton (1993). American apartheid: Segregation and the making of the underclass. Harvard University Press.

Morenoff, Jeffrey D. and Robert J. Sampson (1997). Violent crime and the spatial dynamics of neighborhood transition: Chicago, 1970-1990. Social Forces, 76(1), pp. 31-64.

Morenoff, Jeffrey D., Robert J. Sampson, and Stephen W. Raudenbush (2001). Neighborhood inequality, collective efficacy, and the spatial dynamics of urban violence. Criminology, 39(3), pp. 517-558.

O'Flaherty, Brendan and Rajiv Sethi (2010). The racial geography of street vice. Journal of Urban Economics, 67(3), pp. 270-286.

(2014). Urban crime. In Handbook of Urban and Regional Economics, Elsevier.

Pearl, Judea (2009). Causality: Models, reasoning and inference. Cambridge University Press.

Politis, Dimitris N. and Joseph P. Romano (1994). Large sample confidence regions based on subsamples under minimal assumptions. Annals of Statistics, 22(4), pp. 2031-2050.

Punter, John (2007). The Vancouver achievement: Urban planning and design. UBC Press.

Roncek, Dennis W. and Ralph Bell (1981). Bars, blocks, and crimes. Journal of Environmental Systems, 11(1), pp. 35-47.

Roncek, Dennis W. and Pamela A. Maier (1991). Bars, blocks, and crimes revisited: Linking the theory of routine activities to the empiricism of "hot spots". Criminology, 29(4), pp. $725-753$.

Rosenthal, Stuart S. and Amanda Ross (2010). Violent crime, entrepreneurship, and cities. Journal of Urban Economics, 67(1), pp. 135-149. 
Sampson, Robert J. (1983). Structural density and criminal victimization. Criminology, 21(2), pp. 276-293.

Sampson, Robert J., Stephen W. Raudenbush, and Felton Earls (1997). Neighborhoods and violent crime: A multilevel study of collective efficacy. Science, 277(5328), pp. 918-924.

Sarnoff, Nancy and David Kaplan (2007). High-density, mixed-use trend takes root in Houston. Houston Chronicle.

Shea, John (1997). Instrument relevance in multivariate linear models: A simple measure. Review of Economics and Statistics, 79(2), pp. 348-352.

Sherman, Lawrence W. and Dennis P. Rogan (1995). Effects of gun seizures on gun violence: "Hot spots" patrol in Kansas City. Justice Quarterly, 12(4), pp. 673-693.

Sherman, Lawrence W., Patrick R. Gartin, and Michael E. Buerger (1989). Hot spots of predatory crime: Routine activities and the criminology of place. Criminology, 27(1), pp. $27-56$.

Shertzer, Allison, Tate Twinam, and Randall P. Walsh (2014a). Race, ethnicity, and discriminatory zoning. NBER Working Paper \#20108. (2014b). Zoning and urban persistence. Unpublished manuscript.

Silverman, Gary (2013). New York: A concrete legacy. Financial Times.

Stark, Rodney (1987). Deviant places: A theory of the ecology of crime. Criminology, 25(4), pp. 893-910.

Stucky, Thomas D. and John R. Ottensmann (2009). Land use and violent crime. Criminology, 47(4), pp. 1223-1264.

Weisburd, David and Shai Amram (2014). The law of concentrations of crime at place: The case of Tel Aviv-Jaffa. Police Practice and Research, 15(2), pp. 101-114.

Weisburd, David, Shawn Bushway, Cynthia Lum, and Sue-Ming Yang (2004). Trajectories of crime at places: A longitudinal study of street segments in the city of Seattle. Criminology, 42(2), pp. 283-322.

Weisburd, David L., Elizabeth R. Groff, and Sue-Ming Yang (2012). The criminology of place: Street segments and our understanding of the crime problem. Oxford University Press.

White, Halbert (1980). A heteroskedasticity-consistent covariance matrix estimator and a direct test for heteroskedasticity. Econometrica, 48(4), pp. 817-38. (1982). Maximum likelihood estimation of misspecified models. Econometrica, 50(1), pp. $1-25$.

White, Garland F. (1990). Neighborhood permeability and burglary rates. Justice Quarterly, 7(1), pp. 57-67.

Wirth, Louis (1938). Urbanism as a way of life. American Journal of Sociology, 44(1), pp. $1-24$.

Wirth, Louis and Margaret Furez (1938). Local community fact book. Chicago Recreation Commission.

Wright, Richard T. and Scott H. Decker (1997). Armed robbers in action: Stickups and street culture. Northeastern University Press. 